Volume 117

Issue 4 Dickinson Law Review - Volume 117,

2012-2013

3-1-2013

\title{
Supported Decision-Making: A Viable Alternative to Guardianship?
}

Nina A. Kohn

Jeremy A. Blumenthal

Amy T. Campbell

Follow this and additional works at: https://ideas.dickinsonlaw.psu.edu/dlra

\section{Recommended Citation}

Nina A. Kohn, Jeremy A. Blumenthal \& Amy T. Campbell, Supported Decision-Making: A Viable Alternative to Guardianship?, 117 DICK. L. REV. 1111 (2013).

Available at: https://ideas.dickinsonlaw.psu.edu/dlra/vol117/iss4/7

This Article is brought to you for free and open access by the Law Reviews at Dickinson Law IDEAS. It has been accepted for inclusion in Dickinson Law Review by an authorized editor of Dickinson Law IDEAS. For more information, please contact lja10@psu.edu. 


\title{
Supported Decision-Making: A Viable Alternative to Guardianship?†
}

\author{
Nina A. Kohn, ${ }^{*}$ Jeremy A. Blumenthal** \& Amy T. \\ Campbell***
}

\begin{abstract}
The law has traditionally responded to cognitive disability by authorizing surrogate decision-makers to make decisions on behalf of disabled individuals. However, supported decision-making, an alternative paradigm for addressing cognitive disability, is rapidly gaining political support. According to its proponents, supported decision-making empowers individuals with cognitive challenges by ensuring that they are the ultimate decision-maker but are provided support from one or more others, giving them the assistance they need to make decisions for themselves. This article describes supported

$\dagger$ This article was supported by a grant from the Administration on Aging and the National Institute on Disability \& Rehabilitation Research. An earlier version of this article was presented at a conference entitled Aging with a Disability: Demographic, Social, and Policy Considerations organized by the Center for Aging and Policy Studies at Syracuse University and the Michigan Center on the Demography of Aging at the University of Michigan and held at the U.S. Department of Health \& Human Services in May 2012. Another version was circulated for discussion at an October 2012 roundtable entitled Beyond Guardianship: Supported Decision-Making by Individuals with Intellectual Disabilities, hosted at the New York City Surrogates Court by the American Bar Association (ABA) Commission on Disability Rights and the ABA Commission on Law and Aging, in cooperation with the Administration on Intellectual and Developmental Disabilities in the Administration for Community Living, U.S. Department of Health and Human Services. The authors extend thanks to those participating in the above conference and roundtable for their insights, and to Lisa Iezzoni and Arlene Kanter for their helpful comments on earlier drafts.

* Professor and Judith Greenberg Seinfeld Distinguished Faculty Fellow, Syracuse University College of Law. J.D., Harvard Law School; A.B., Princeton University.

** Professor, Syracuse University College of Law. J.D., University of Pennsylvania Law School; A.B., A.M., Ph.D., Harvard University.

*** Associate Professor, Center for Bioethics and Humanities and Department of Psychiatry, Upstate Medical University. M. Bioethics, University of Pennsylvania; J.D., Yale Law School; B.A., University of Notre Dame.
\end{abstract}


decision-making and its normative appeal. It then provides a descriptive account of how supported decision-making works based on the empirical literature on supported decision-making as well as that on shared decision-making, a related model used in medical contexts. The article shows how employing supported decision-making in lieu of guardianship, or integrating it into the guardianship system, has the potential to promote the self-determination of persons with intellectual and cognitive disabilities consistent with international and national legal norms. However, we find that, despite much rhetoric touting its advantages, little is known about how supported decision-making processes operate or about the outcomes of those processes. Further research is necessary to design and develop effective supported decisionmaking systems. We therefore propose a series of research questions to help inform policy choices surrounding supported decision-making.

\section{Table of Contents}

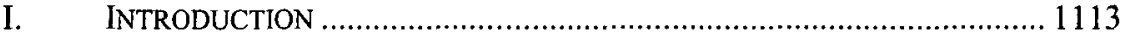

II. THE CALL FOR SUPPORTED DECISION-MAKING................................. 1114

A. The Current Approach: Surrogate Decision-Making ................ 1115

B. The Paradigm Shift: Supported Decision-Making .................... 1120

1. Models of Supported Decision-Making ............................ 1121

2. Proposals for Integrating Supported Decision-Making into U.S. Legal Systems ........................................................... 1124

3. The Appeal of Supported Decision-Making ...................... 1126

III. THE EVIDENCE BASE FOR SUPPORTED DECISION-MAKING................ 1128

A. Research on Supported Decision-Making Utilization................ 1130

1. Frequency of Utilization .............................................. 1130

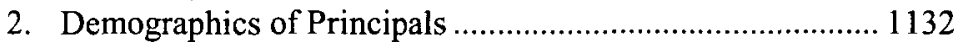

3. Demographics of Supporters............................................ 1134

4. Impact of Race and Ethnicity ........................................... 1135

B. Research on Supported Decision-Making Outcomes................ 1135

1. Process Outcomes ........................................................... 1136

2. Substantive Outcomes................................................. 1138

a. Psychological Impacts on Principals .......................... 1138

b. Congruency Between Wishes and Decisions................. 1140

c. Quality of Decisions Made ....................................... 1141

d. Psychological Impact on, and of, Supporters................ 1143

3. Effect of Individual Differences and Context on Outcomes 1144

a. Individual Factors ........................................................ 1144

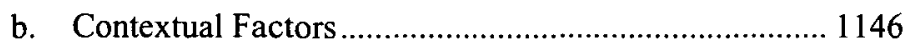

IV. IMPLICATIONS OF RESEARCH ON SHARED DECISION-MAKING ........... 1146

V. NEXT STEPS ........................................................................... 1154

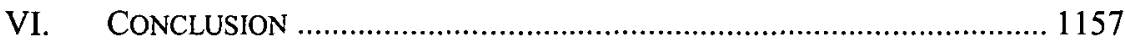




\section{INTRODUCTION}

While all people can struggle to reach satisfying decisions, persons with intellectual and cognitive disabilities face additional and often profound challenges when doing so. The U.S. legal system has historically responded to these challenges by creating mechanisms that authorize others to make decisions for persons with intellectual and cognitive disabilities. The most powerful and important of these surrogate decision-making mechanisms is a guardianship proceeding, in which a court appoints a third party to make decisions for a person with a disability.

The use of surrogate decision-making and guardianship, however, is coming under increasing criticism from disability rights advocates and scholars who urge replacing it—or at least supplementing it-with a process called "supported decision-making." Proponents of supported decision-making tout it as a means to empower persons with disabilities by providing them with help in making their own decisions, rather than simply providing someone to make decisions for them. Their impassioned call to replace surrogate decision-making (sometimes referred to as "substitute decision-making") with supported decisionmaking is rapidly gaining political momentum. This momentum is attributable in part to the adoption of the United Nations Convention on the Rights of Persons with Disabilities (CRPD), which includes language that embraces supported decision-making and which is seen by some as requiring nations to adopt supported decision-making mechanisms.

Despite the growing interest in supported decision-making, this article represents the first systematic attempt to evaluate the claims and arguments made by its promoters. Whereas previous writing on the topic has focused almost exclusively on the normative arguments in favor of supported decision-making, we seek to inform the supported decisionmaking debate by determining how its processes actually operate in practice. To do so, we not only analyze the limited empirical literature on supported decision-making but also draw insight from the literature on "shared decision-making," a related approach that has been promoted in medical settings. Our review of this literature allows us to identify what policymakers need to know about supported decision-making in order to determine whether it should be incorporated into surrogate decision-making processes, used in lieu of surrogate decision-making processes, or rejected altogether.

We conclude that, although supported decision-making presents an appealing alternative to guardianship and therefore policymakers in the United States should give serious consideration as to how it might be incorporated into public policy, there is currently insufficient empirical 
evidence to know the extent to which (or the conditions under which) it can remedy the problems posed by surrogate decision-making processes. Specifically, we find that, despite years of use, there is almost no evidence as to how decisions are actually made in supported decisionmaking relationships; the effect of such relationships on persons in need of decision-making assistance; or the quality of the decisions that result. Without more information, it is impossible to know whether supported decision-making actually empowers persons with cognitive and intellectual disabilities. Furthermore, there is reason to be concerned that supported decision-making might actually have the opposite effect, disempowering such individuals or making them more vulnerable to manipulation, coercion, or abuse. Therefore, in addition to making policy recommendations, we suggest a series of research questions designed to increase the likelihood that policymakers will have the information they need to evaluate supported decision-making and the claims of its proponents.

This article proceeds in four major Parts. Part II explores criticisms of the U.S. legal system's current approach to addressing decisionmaking challenges faced by persons with cognitive and intellectual disabilities, the ways in which implementation of supported decisionmaking could fundamentally alter that approach, and the normative arguments in favor of such a shift. Part III explores the empirical literature on supported decision-making and not only discusses what that literature shows but also identifies the important questions this literature fails to answer. ${ }^{1}$ Part IV then suggests how research on shared decisionmaking (a related decision-making paradigm) might inform policy and research on supported decision-making. Finally, Part V makes a series of recommendations for policy and future research.

\section{THE CALL FOR SUPPORTED DECISION-MAKING}

Individuals with intellectual disabilities (ID) or other forms of cognitive disability can face significant decision-making challenges. Some of these challenges are the result of their underlying disabilities, which make analytical and other cognitive tasks more difficult for them. Other challenges are the result of their social environment. For example, stereotypical thinking about persons with ID may result in their being

1. A condensed review of the findings from the empirical literature on supported decision-making can be found in Nina A. Kohn \& Jeremy A. Blumenthal, $A$ Critical Assessment of Supported Decision-Making for Persons with Intellectual Disabilities, DisABILITY \& HEALTH J. (forthcoming 2013), published in conjunction with the May 2012 conference noted above. 
denied the opportunity to develop and practice decision-making skills. ${ }^{2}$ These decision-making challenges typically increase and evolve as such individuals grow older. For example, the primary source of decisionmaking assistance for persons with $\mathrm{ID}$ is typically their parents. ${ }^{3}$ Existing decision-making systems can become destabilized and may even disappear as these parents themselves age and increasingly predecease their children. As a result, persons with ID may be confronted with the need to establish new systems for obtaining the help they need in making everyday decisions. In addition, such transitions may precipitate the need to make momentous life decisions, ${ }^{4}$ such as the decision of where to live after the death of a parent with whom the person with ID resided. ${ }^{5}$

In this Part, we describe the legal system's current approach to addressing the decision-making challenges faced by such individuals and the growing critique of that approach. We then explore how such challenges might be addressed under an alternative, supported decisionmaking paradigm in which a person with the disability is the ultimate decision-maker but receives support from other people as well. Specifically, we provide an overview of supported decision-making, the arguments in favor of its use, and the potential advantages it might afford persons with cognitive and intellectual disabilities.

\section{A. The Current Approach: Surrogate Decision-Making}

The U.S. legal system's primary response to the decision-making challenges faced by persons with cognitive and intellectual disabilities is to provide for the appointment of surrogate (or "substitute") decision-

2. See Barbara L. Ludlow, Life After Loss: Legal Ethical and Practical Issues, in Aging, Rights and Quality of Life: Prospects For Older PeOPle with Developmental Disabilities 189, 197 (Stanley S. Herr \& Germain Weber eds., 1999) (suggesting that decision-making is a skill that can be learned); ROBERT M. LEVY \& Leonard S. Rubenstein, The Rights of People with Mental Disabilities 106 (1996) (noting that many persons with ID "are frequently not allowed to participate in decision making to the extent of their abilities").

3. See Christine Bigby, Ageing with a Lifelong Disability 193 (2004).

4. Both types of challenges are exacerbated by the fact that many families do not adequately plan for these transitions. See Tamar Heller \& John Kramer, Involvement of Adult Siblings of Persons with Developmental Disabilities in Future Planning, 47 INTELL. \& Developmental Disabilities 208, 208 (2009) (citing research indicating that only between $25 \%$ and $50 \%$ of families of adults with developmental disabilities have made plans for future living arrangements); BIGBY, supra note 3, at 204 ("Most studies show that only between one-third and one-half of parents make concrete plans for the future of an adult with intellectual disability who is living at home.").

5. Cf. BIGBY, supra note 3, at 161 (stating that most adults with intellectual disabilities live with their parents "well into middle age" and showing how parental aging and death precipitate difficult decisions about housing). 
makers for them. Typically, the appointment is made through a guardianship proceeding, a court proceeding in which a judge appoints a third party (called a "guardian") to make some or all decisions on behalf of an incapacitated individual (called a "ward"). ${ }^{6}$ Indeed, many states effectively encourage guardianship over persons with ID by creating special, streamlined processes for obtaining guardianship over persons with ID or developmental disabilities that are not available for persons with other disabilities. ${ }^{7}$ These specialized processes can reduce the barriers to obtaining guardianship and can also encourage the use of plenary guardianships-those that cover all types of decisions, as opposed to decisions about select issues, such as finances. ${ }^{8}$

Although guardianship is the most comprehensive method for legally empowering surrogate decision-makers, other surrogate decisionmaking mechanisms also exist. Some states have created processes by which third parties can make surrogate decisions for persons with ID without specific court authorization. For example, New York State empowers panels of four volunteers (which by law must include both a health care professional and an attorney) to make major medical treatment decisions in state-operated or state-licensed facilities. ${ }^{9}$ The Social Security Administration can appoint a third party (called a "representative payee") to manage an individual's public benefits

6. As state law governs the guardianship process, its procedural requirements vary somewhat from state to state. Key differences include how states define "incapacity" for the purposes of imposing a guardianship, how states select a guardian for a ward, the extent and nature of state supervision over the guardian once appointed, and the extent and nature of due process protections provided to would-be wards. Guardianship proceedings are initiated by an interested party who files a petition with the appropriate court, alleging that an individual cannot make all or some decisions on his own behalf and that, therefore, the state should appoint a guardian to make decisions for him. This triggers a court fact-finding process to determine whether a guardianship should be imposed and, if so, who should serve as guardian. As the result of such a proceeding, a court can deny the petition, grant a plenary guardianship, or grant a limited guardianship. In a plenary guardianship, the ward is completely stripped of his or her legal decisionmaking capacity; in a limited guardianship, by contrast, the ward retains certain forms of decision-making power. Some states also differentiate between guardianship over the person (in which the guardian is granted the right to make personal and health care decisions for the ward) and conservatorship (in which the guardian is granted the right to make financial decisions for a ward). Increasingly, however, the term "guardianship" is used to refer to both situations. See Nina A. Kohn, Elder Law: Cases, Problems, EXERCISES (forthcoming 2013). (2012).

7. See, e.g., Ala. CodE $\S 12-13-21$ (2012); N.Y. SurR. CT. Proc. ACt $\S 1750$

8. For one court's thoughtful and disconcerting explanation of the issue, see In re Chaim A.K., 885 N.Y.S.2d 582 (N.Y. Surr. Ct. 2009) (discussing the difference between the Article 17-A guardianship and Article 81 guardianship in New York).

9. See NY MENTAL HYG. L. art. 80 (McKinney's 2013); see also LeVY \& RUBENSTEN, supra note 2, at 107. 
without triggering a court process. In addition, despite misconceptions to the contrary, many persons with cognitive and intellectual disabilities can themselves appoint surrogate decision-makers by executing powers of attorney or advance directives for health care. ${ }^{10}$

Even so, in recent years, disability rights scholars and advocates, both in the United States and internationally, have challenged the appropriateness and acceptability of guardianship for persons with disabilities, especially those with ID. One concern is that guardianship law is frequently misapplied, with significant consequences for individuals' basic civil rights and civil liberties." The guardianship system is designed as a last resort, applied only when an individual lacks capacity to make decisions. However, there is reason to believe that guardianships are imposed on many individuals without sufficient evidence of their decision-making incapacity ${ }^{12}$ and that, in some cases, disability alone appears to be used as a sufficient justification for the imposition of guardianship. ${ }^{13}$ Thus, rather than being treated as the extraordinary proceedings that they are, guardianships are often treated

10. See Gary L. Stein, U.S. Dep't of Health \& Human Servs., Advance Directives and Advance Care Planning for People with InTellectual and PHYSICAL DisABILITIES (2007), available at http://aspe.hhs.gov/daltcp/reports/2007/ adacp.htm (discussing the ability of persons with ID to engage in advance care directives); Marshall Kapp, Health Care DecisionMaking, in AGING, RIGHTS AND QUALITY OF LIFE, supra note 2, at 45, 53 (stating that "many older adults with mental retardation are capable and, with adequate and timely counseling, desirous of executing a proxy directive when a close family member or friend is available to serve in the surrogate role," and noting that less capacity may be needed to appoint a surrogate decision-maker than to make the ultimate health care decision the surrogate is appointed to make).

11. See, e.g., Guardianship, THE ARC (Oct. 29, 2009), http://www.thearc.org/page. aspx?pid=2351 ("Guardianship has been over-used by those who were unaware of less intrusive alternatives or who simply wanted to have their views prevail over the wishes of the individual. Frequently, lesser forms of legal intervention, such as limited guardianship and use of powers of attorney or advance directives, have been either overlooked, intentionally avoided, or unavailable.").

12. See Pamela B. Teaster et al., Wards of the State: A National Study of PUBLIC GUARDIANSHIP 15-16 (2005) (discussing research and evidence on the misuse of guardianship, including a 1994 national study by the Center for Social Gerontology finding that the majority of guardianship hearings last less than 15 minutes); Lawrence A. Frolik, Guardianship Reform: When the Best is the Enemy of the Good, 9 STAN. L. \& POL'Y REV. 347, 354 (1998) (noting that, "as long as the law permits plenary guardianship, courts will prefer to use it[,]" even though plenary guardianship is only appropriate in a sub-set of cases, and urging those promoting guardianship reform to prioritize educating judges about limited guardianship).

13. See Dorothy Squatrito Millar, Age of Majority, Transfer of Rights and Guardianship: Consideration for Families and Educators, 38 EDUC. \& TRAINING IN Developmental Disabilities 378, 390 (2003) (noting that "disability alone does not equate with incapacity resulting in a need for guardianship," despite a tendency to treat it as such). 
as a routine part of permanency planning for persons with ID. ${ }^{14}$ Significant reforms have been implemented to reduce the overbreadth of guardianship orders by encouraging the use of limited guardianships in lieu of plenary ones; nevertheless, these reforms have had remarkably little effect on judicial behavior. ${ }^{15}$ The result is that guardianshipsincluding plenary guardianships-appear to be routinely granted over persons with ID.

The excessive use of guardianship and, in particular, the use of excessively broad guardianship orders is a problem that is not limited to wards with ID. ${ }^{16}$ However, the over-imposition of guardianship may be an especially acute problem for persons with ID because guardianship proceedings are frequently treated as a central part of permanency planning for adults with ID. ${ }^{17}$ Moreover, caregivers of persons with ID may be pushed to apply for guardianship in order to access or manage benefits. For example, provisions in the Individuals with Disabilities Education Act (IDEA) encourage parents to obtain guardianship over their children with ID in order to continue to manage their children's public education benefits after they reach the age of majority. ${ }^{18}$

Another criticism is that the guardianship system in its current form is unlawful even if properly applied. Specifically, some critics have assailed the concept of guardianship as inconsistent with Article 12 of the CRPD. ${ }^{19}$ Article 12 states that "persons with disabilities enjoy legal

14. See Ludlow, supra note 2, at 198 ("Assignment of a guardianship to parents is all too often a rite of passage for people with developmental disabilities as they enter adulthood.'); BIGBY, supra note 3, at 203-04 (2004) (describing guardianship as part of the standard practice of planning for the future of persons with ID).

15. See Frolik, supra note 12, at 349,354 (explaining that limited guardianships are rarely ordered, even when legally appropriate); Pamela B. Teaster et al., Wards of the State: A National Study of Public Guardianship, 37 Sterson L. REv. 193, 233 (2007) (reporting, based on a national study, that "[c]ourts rarely appoint the public guardian as a limited guardian").

16. Jennifer Moye et al., Clinical Evidence in Guardianship of Older Adults Is Inadequate: Findings from a Tri-State Study, 47 GERONTOLOGIST 604 (2007) (in a study of guardianships of people age 55 and older, discussing the larger problem of inadequate clinical bases for guardianship).

17. See sources cited supra note 14 and accompanying text.

18. Millar, supra note 13, at 390 (noting that the IDEA states that students are to be decision-makers once they reach the age of majority unless they are considered to be incompetent).

19. See Michael L. Perlin, "Striking for the Guardians and Protectors of the Mind": The Convention on the Rights of Persons with Mental Disabilities and the Future of Guardianship Law, 117 PENN STATE L. REV. 1159, 1177 (2013) ("The Convention forces us to abandon substituted decisionmaking paradigms and to replace them with supported decisionmaking ones."); TINA MINKOWITZ, SUBMISSION TO THE COMMITTEE ON THE Rights of Persons with Disabilities, Day of GENERAL Discussion On CRPD ARTICLE 12 (2010) (declaring guardianship and all other forms of substituted decision-making to be contrary to the CRPD); $c f$. Robert D. Dinerstein, Implementing Legal Capacity Under 
capacity on an equal basis with others in all aspects of life."20 Some have interpreted this Article as inconsistent with state removal of legal capacity through the guardianship system, ${ }^{21}$ or at least with plenary guardianship. $^{22}$ Arguably, overuse of guardianships also constitutes disability discrimination in violation of the Americans with Disabilities Act (ADA) insofar as individuals are not provided with reasonable, less restrictive alternatives to guardianship. ${ }^{23}$

A third concern is that guardianship is anti-therapeutic. ${ }^{24}$ Guardianship need not mean that wards are not involved in making decisions about their lives. ${ }^{25}$ Current systems, however, do not promote such involvement ${ }^{26}$ and may leave wards feeling isolated and lonely. ${ }^{27}$

Article 12 of the UN Convention on the Rights of Persons with Disabilities: The Difficult Road from Guardianship to Supported Decision-Making, 19 HUM. RTS. BRIEF 8 (2012) (discussing different countries' responses to Article 12 in relation to guardianship).

20. Convention on the Rights of Persons with Disabilities (CRPD) art. 12, G.A. Res. 61/106, U.N. Doc. A/RES/61/106 (Dec. 13, 2006). Notably, this is a departure from the approach of the 1971 Declaration of the Rights of Mentally Handicapped, which stated that "the mentally retarded person has a right to a qualified guardian when this is required to protect his personal well-being and interests." ANDREAS DiMOPOULOS, ISSUES IN Human Rights Protection of InTELlectually Disabled Persons 69 (2010).

21. See Amita Dhanda, Legal Capacity in the Disability Rights Convention: Stranglehold of the Past or Lodestar for the Future?, 34 SYRACUSE J. INT'L L. \& COM. 429, 460-62 (2007) (arguing that, while the language of Article 12 does not prohibit substituted decision-making, reading Article 12 in light of the process that led to its creation supports interpreting it as doing so).

22. See Barbara Carter, Adult Guardianship: Human Rights or Social Justice?, 18 J.L. \& MED. 143 (2010), available at http://www.publicadvocate.vic.gov.au/file/file/ Research/Adult Guardianship.pdf (describing the active debate over whether Article 12 permits guardianship). But see Dhanda, supra note 21, at 460-61 (arguing that the CRPD should be read as promoting the recognition that persons with disabilities have full legal capacity but acknowledging that "[t]he text of Article 12 does not prohibit substituted decision-making and there is language which could even be used to justify substitution").

23. See Leslie Salzman, Rethinking Guardianship (Again): Substituted Decision Making as a Violation of the Integration Mandate of Title II of the Americans with Disabilities Act, 81 U. Colo. L. REV. 157 (2010) [hereinafter Salzman, Rethinking Guardianship] (arguing that the United States' current approach to guardianship violates the ADA's mandate that services be provided in the most integrated and least restrictive manner).

24. See, e.g., Jennifer Wright, Guardianship for Your Own Good: Improving the Well-Being of Respondents and Wards in the USA, 33 INT'L J.L. \& PSYCHIATRY 350 (2010) (discussing a variety of ways in which guardianship can be anti-therapeutic).

25. Pamela Teaster, The Wards of Public Guardians: Voices of the Unbefriended, 51 FAM. RELATIONS 344, 348 (2002) (in a qualitative study interviewing 13 wards of public guardians, finding that four contributed to decisions about daily activities).

26. Id. (in a qualitative study interviewing 13 wards of public guardians, finding that there was an absence of documentation in wards' case files about wards' "needs and wishes, such as a values history").

27. Id. (in a qualitative study interviewing 13 wards of public guardians, finding such sentiments common); Salzman, Rethinking Guardianship, supra note 23, at 163 (describing guardianship as creating "constructive isolation"). 
Guardianship may also undermine wards' physical and psychological well-being by reducing their sense of control over their own lives. ${ }^{28}$ Ironically, such anti-therapeutic effects may be the cost of obtaining needed, or at least beneficial, services and support. For example, The Arc, a leading advocacy and service organization for persons with intellectual and development disabilities, explains that caregivers may feel forced into obtaining guardianship over a person with ID in order to help the individual access medical care and other supports. ${ }^{29}$

Finally, there is a moral critique of surrogate decision-making, and especially guardianship, as an affront to the humanity of those subject to it. For example, Canadian disability rights advocate Michael Bach has declared guardianship to be "[s]tate-sanctioned removal of personhood from an individual with respect to one or more or all areas of personal decision-making." 30 Others have characterized imposition of guardianship as a form of "civil death." 31

\section{B. The Paradigm Shift: Supported Decision-Making}

In light of these serious concerns, critics of guardianship and surrogate decision-making have suggested replacing that approach with "supported decision-making." As a general matter, supported decisionmaking occurs when an individual with cognitive challenges is the ultimate decision-maker but is provided support from one or more persons who explain issues to the individual and, where necessary, interpret the individual's words and behavior to determine his or her preferences. ${ }^{32}$ However, some advocates do not use the term "supported decision-making" this broadly. Instead, they reserve the term for situations in which the person being supported has voluntarily entered into the arrangement, and these advocates use terms like facilitated decision-making and co-decision-making to describe other versions of

28. See Wright, supra note 24 , at $355-56$ (arguing that guardianship may harm individuals by reducing their sense of control).

29. See THE ARC, supra note 11.

30. Michael Bach, PowerPoint, Legal Capacity, Personhood and Supported Decision Making, Can. Ass'n for Cmty Living (U.N. Enable Working Group, Jan. 2006), available at http://www.un.org/esa/socdev/enable/rights/ahc7docs/ahc7ii3.ppt.

31. See, e.g., Perlin, supra note 19, at 1162 (endorsing this view, at least with regard to the use of guardianship in certain jurisdictions).

32. See Untted Nations Enable, Handbook for Parliamentarians on the CONVENTION OF Rights OF PERSONS WITH Disabilities ch. 6 (2007), available at http://www.un.org/disabilities/default.asp?id $=212$ (providing a parallel but longer definition); Michael Bach \& Lana Kerzner, a New Paradigm for Protecting AUTONOMY AND THE RIGHT TO LEGAL CAPACITY (2010), available at http://www.lcocdo.org/disabilities/bach-kerzner.pdf. 
supported decision-making. ${ }^{33}$ Further confusing the definition of supported decision-making is the fact that many of the statutory schemes widely described as enabling supported decision-making have features that are inconsistent with how its promoters typically define supported decision-making. For example, as noted below, there is a tendency to describe supported decision-making as providing the principal with full control over what decisions are made, even when the underlying law provides exceptions to this approach. ${ }^{34}$

\section{Models of Supported Decision-Making}

There is no single model of supported decision-making. ${ }^{35}$ Supported decision-making can be purely informal--something done without legal sanction or legal enforceability. Alternatively, it can be formalized through a private but legally enforceable or legally significant agreement between the person with a disability and a trusted third party. Such formalized supported decision-making relationships, in turn, may be pre-existing relationships to which the state gives legal recognition, ${ }^{36}$ or they may be new relationships created for the purpose of providing state-sanctioned support.

Perhaps the most frequently cited model of supported decisionmaking is British Columbia's Representation Agreement. British Columbia is one of several Canadian provinces that have statutorily enabled private contracts as alternatives to guardianship. ${ }^{37}$ In British Columbia, an adult may enter into a Representation Agreement that

33. For a discussion of these different definitions, see LANA KERZNER, PAVING THE WAY to Full REALIZATION OF THE CRPD'S Rights TO LEGAL CAPACITY AND SUPPORTED Decision-MAKING: A CANAdiAn Perspective (2011), available at http://www.anth.ubc.ca/fileadmin/user_upload/ClC/documents/In_From_The_Margins_P aper-Lana_Kerzner-FINAL-April_22_2011_2_pdf; BACH \& KERZZNER, supra note 32.

34. See, e.g., BACH \& KERZNER, supra note 32 , at 90 (recognizing the reasonableness limitation in the British Columbia model but then stating that the supporter in that system is always bound by the wishes and instructions of the principal). In addition, while most definitions of supported decision-making do not include (and indeed, often explicitly exclude) the use of advance planning tools by which a person appoints a surrogate decision-maker (e.g., health care proxies and durable powers of attorney), even this is not uniformly the case. See Soumitra Pathare \& Laura S. Shields, Supported DecisionMaking for Persons with Mental Illness: A Review, 34 Pub. Health Revs. 1, 4 (2012) (describing such advance planning tools as a form of supported decision-making).

35. See Leslie Salzman, Guardianship for Persons with Mental Illness-A Legal \& Appropriate Alternative?, 4 ST. LouIS U. J. HEALTH L. \& POL'Y 279, 306 (2011) [hereinafter Salzman, Guardianship for Persons].

36. See Terry Carney, Participation and Services Access Rights for People with Intellectual Disability: A Role for Law?, 38 J. INTELL. \& DEVELOPMENTAL DisABILITY 59, 60 (2013) (noting that supported decision-making is frequently described as simply recognizing existing social structures).

37. See BACH \& KERZNER, supra note 32, at 53. 
authorizes a third party to act on his or her behalf for a broad range of personal decisions as well as many, but not all, financial decisions. The person creating the Agreement retains his or her full legal capacity, can revoke the Agreement at any time, and must be consulted by the representative. ${ }^{38}$ There is only a minimal capacity requirement ${ }^{39}$ to enter into a standard Representation Agreement (i.e., one that does not delegate certain powers, such as the ability to make decisions about placement in a nursing home or refusal of life-sustaining treatment), ${ }^{40}$ and there is a presumption that all people are capable of entering into one absent a showing to the contrary. ${ }^{41}$ Consequently, a person who would not have sufficient capacity to execute an enduring power of attorney or other form of contract may enter into a standard Agreement. ${ }^{42}$

Ordinarily, under the British Columbia approach, a representative acting according to a Representation Agreement must, consistent with common conceptions of supported decision-making, consult with the principal and comply with his or her wishes. ${ }^{43}$ Even so, the model actually empowers a representative to act in a way inconsistent with full self-determination for the principal: statutorily, the representative need only consult with the principal "to the extent reasonable"44 and need only comply with the principal's wishes "if reasonable to do so."45 This is one example of ways in which the description of these models by those calling for supported decision-making is somewhat inconsistent with the underlying statutes governing these models. ${ }^{46}$

38. In British Columbia, the charity Nidus Personal Planning Resource Centre helps individuals form Representation Agreements, and its website is a valuable explanatory resource. See Representation Agreement, NIDUS, http://www.nidus.ca/?page id=50/ (last visited Mar. 22, 2013).

39. See Representation Agreement Act, R.S.B.C. 1996, ch. 405, pt. 2.8 (Can.) (providing that an adult may enter into a standard Representation Agreement despite being "incapable of (a) making a contract, (b) managing his or her health care, personal care or legal matters, or (c) the routine management of his or her financial affairs").

40. See id. pt. 2.4 (simply stating that "[a]n adult may make a representation agreement unless he or she is incapable of doing so" but not defining what it means to be incapable of doing so).

41. See id. pt. 1.3 ("Until the contrary is demonstrated, every adult is presumed to be capable of (a) making, changing or revoking a representation agreement, and (b) making decisions about personal care, health care and legal matters and about the routine management of the adult's financial affairs.").

42. See id. pt. 2.8 (setting forth the test of incapability for standard agreements).

43. See id. pt. 3.16 (setting forth the duties of the representative).

44. Representation Agreement Act, R.S.B.C. 1996, ch. 405, pt. 3.16 (Can.).

45. Id.

46. See, e.g., BACH \& KERZNER, supra note 32, at 90 (recognizing the reasonableness limitation in the British Columbia model but then stating that the supporter in that system is always bound by the wishes and instructions of the principal). 
Although supported decision-making is typically presented as involving a single decision-making supporter, private supported decision-making relationships may also occur in the context of a "circle of support" or a "microboard." A circle of support is a group of people, typically family members and friends, who meet regularly with a person with a disability to help that person formulate and realize his or her hopes or desires. Circles of support are seen as a way of creating or reinvigorating a support network for a person with a disability, ${ }^{47}$ which may be especially important for persons with ID experiencing generational transitions in their support network. A microboard is similar to a circle of support in that it is also comprised of a group of people who aim to help an individual meet his or her needs in a manner consistent with his or her hopes and desires. However, the term "microboard" is typically used to refer to organizations that are more formal: non-profit organizations formed to support and, in some cases, to act as the service provider for an individual with a disability. ${ }^{48}$ To the extent that a circle of support helps a person understand various life choices and choose among them, or that a microboard is structured to allow the person with a disability to direct its actions (e.g., such as by having that individual serve as the President of the Board), ${ }^{49}$ both approaches can be mechanisms for implementing supported decisionmaking. By contrast, if the members of a micro-board or circle of support ultimately make decisions on behalf of the person with a disability even if they consult with that person and consider the person's wishes - then such arrangements should not be classified as supported decision-making.

Alternatively, supported decision-making can be accomplished through public appointment. ${ }^{50}$ For example, Sweden provides for the

47. See, e.g., Allison Rowlands, Ability or Disability?: Strengths-based Practice in the Area of Traumatic Brain Injury, 82 FAMILIES IN SOC. 273, 274 (2001) (describing circles of support as "a contrived, purpose-built friendship network, established and facilitated by a worker or trained volunteer, to replace or re-invigorate the natural network of a person whose disability may have led to former friends dropping away ...").

48. For a discussion of the work and impact of three successful microboards, see Paul H. Malette, Lifestyle Quality and Person-Centered Support: Jeff, Janet, Stephanie, and the Microboard Project, in Person-Centered Planning 151 (Steve Holburn \& Peter M. Vietze eds., Paul Brooks Publishing 2002).

49. For descriptions of microboards and their structures, see JACKIE L. GOLDEN, INCLUSION RESEARCh INST., SElF-DiReCTED SUPPORT CORPORATIONS (n.d.), available at http://www.reinventingquality.org/docs/golden.pdf; Kristi Dezonia, Microboards: An Option in Life Span Supports, 39 THE EXCEPTIONAL PARENT 56 (2009).

50. See Salzman, Guardianship for Persons, supra note 35, at 307-09 (dividing supported decision-making approaches into two major groups: private agreement approaches and court-appointed approaches). 
appointment of a god man, which translates roughly as "good man" or "mentor," who can provide many of the services that a guardian would provide in the United States. Appointment of a god man does not affect the legal capacity of the recipient. The god man concept contains a central paradox: the god man is said to act with the consent of the person with cognitive challenges and to be limited in his or her ability to act without that consent; however, the god man can be appointed without consent and for an individual who lacks capacity to provide consent. ${ }^{51}$ The Canadian province of Saskatchewan takes an approach similar to that of Sweden, but one that works through the court system instead of through municipal government. ${ }^{52}$ Specifically, Saskatchewan authorizes its courts to appoint a co-decision-maker for personal and/or property decisions for people whose cognitive capacity is impaired to the extent that they require assistance. ${ }^{53}$ Unlike a guardian, the co-decision-maker must "acquiesce in any decision made by the adult provided that a reasonable person could have made that decision and the decision is not likely to result in a loss to the adult's estate. ${ }^{, 54}$ Co-decision-makers are also explicitly required to maximize the participation of the person they assist in decisions with which they are assisting. ${ }^{55}$

\section{Proposals for Integrating Supported Decision-Making into U.S. Legal Systems}

Just as there are a variety of supported decision-making models, the call to formalize supported decision-making takes several forms. First, there have been proposals to integrate supported decision-making into existing guardianship structures. The 2011 National Guardianship Network convened the Third National Guardianship Summit, an interdisciplinary consensus conference that brought together experts from across the United States. The Summit released a series of recommendations for guardianship reform that implicitly called for the incorporation of supported decision-making components into the existing

51. Stanley S. Herr, Self-Determination, Autonomy, and Alternatives for Guardianship, in The Human Rights of PeRsons with InTEllectual Disabilities: DIFFERENT BUT EQUAL 429, 433 (Stanley S. Herr et al. eds., 2003).

52. See Doug Surtees, The Evolution of Co-Decision-Making in Saskatchewan, 73 SASK. L. REV. 75 (2010) (describing Saskatchewan's system).

53. See BACH \& KERZNER, supra note 32 , at 55 (distinguishing co-decision making from supported decision making on the grounds that the subject does not voluntarily enter into the arrangement); Surtees, supra note 52 (describing when appointment of a codecision maker is authorized under Saskatchewan law).

54. Surtees, supra note 52 , at 85.

55. See id. 
guardianship system. ${ }^{56}$ Many of the recommendations took the form of recommended "standards," calling for the ward to be involved in decision-making about his or her life. The recommendations included an overall call for guardians to engage in "person-centered planning," defined by the Summit as an approach that seeks to "discover, understand, and clearly describe the unique characteristics of an individual," with the aim of ensuring that an individual is supported in a "web of relationships," is valued for his or her contributions to the community, and has control over his or her own life. ${ }^{57}$ Supportive elements were also incorporated into a number of more specific standards. For example, in the context of residential decisions, the Summit recommended that guardians "do everything possible to help the person express his or her goals, needs or preferences" if he or she has difficulty doing so. ${ }^{58}$ In the context of financial decision-making, the Summit recommended that wards be "encourage[d] ... to act on [their] own behalf and to participate in decisions," 59 and be assisted in developing or regaining capacity to make decisions. ${ }^{60}$ Second, some have called for establishing supported decision-making structures as an alternative to guardianship, thereby diverting some or most would-be wards into an alternative model. ${ }^{61}$ This approach is consistent with the concept of guardianship as a last resort. As Salzman has observed,

56. Cf. Kristin Booth Glen, Changing Paradigms: Mental Capacity, Legal Capacity, Guardianship \& Beyond, 44 COLUM. HuM. RTS. L. REV. 93 (2012) (describing how supported decision-making principles came to be incorporated into the Summit's recommendations).

57. Symposium, Third National Guardianship Summit Standards and Recommendations, 2012 UTAH L. REV. 1191, 1192 (2012).

58. Id. at 1197 .

The guardian shall identify and advocate for the person's goals, needs, and preference. Goals are what are important to the person about where he or she lives, whereas preferences are specific expressions of choice. First, the guardian shall ask the person what he or she wants. Second, if the person has difficulty expressing what he or she wants, the guardian shall do everything possible to help the person express his or her goals, needs, and preferences. Third, only when the person, even with assistance, cannot express his or her goals and preferences, the guardian shall seek input from others familiar with the person to determine what the individual would have wanted. Finally, only when the person's goals and preferences cannot be ascertained, the guardian shall make a decision in the person's best interest. Id.

59. Id. at 1194 .

60. Id.

61. See, e.g., Salzman, Guardianship for Persons, supra note 35 (arguing that states should embrace supported decision-making as an alternative to guardianship and that doing so may be required by the Americans with Disabilities Act); Glen, supra note 56 (arguing that guardianship should be reserved for only the most extreme cases of incapacity, and showing why fewer cases may satisfy this criterion than commonly thought). 
guardianship cannot truly be a last resort unless there are meaningful alternatives to it. $^{62}$ Notably, there is overlap between these two approaches in that a jurisdiction could both create supported decisionmaking alternatives to guardianship and incorporate supported decisionmaking elements into guardianship proceedings. ${ }^{63}$

Finally, some advocates and scholars have recommended that the court-based guardianship system be abolished in favor of supported decision-making mechanisms, while others have called for abolishing plenary guardianship in favor of supported decision-making but would accept retaining limited guardianship. ${ }^{64}$ Either approach would be a departure from the current practice in countries seen as models for supported decision-making, as all retain guardianship as a safety net. ${ }^{65}$

\section{The Appeal of Supported Decision-Making}

Despite this variation in types of calls for supported decisionmaking, they all share a common recognition that persons with cognitive and intellectual disabilities typically require more support to make decisions than persons without such disabilities, and embrace a role for

62. Salzman, Guardianship for Persons, supra note 35, at 312.

63. See OfFice OF THE Pub. Advocate, SuPPorted Decision-Making: BACKGROUND AND DISCUSSION PAPER 17 (2009) (stating that "[m]any of the principles of supported decision-making can be incorporated into guardianship legislation[,]" but also suggesting the adoption of supported decision-making alternatives to guardianship).

64. See, e.g., Eur. COMm'R H.R., Issue Paper, Who Gets to Decide? Right to Legal Capacity for Persons with Intellectual and Psychosocial Disabilities (2012), available at https://wcd.coe.int/ViewDoc.jsp?id=1908555 (advocating for abolishment of plenary guardianship); Nandini Devi et al., Moving Towards Substituted or Supported Decision-Making? Article 12 of the Convention on the Rights of Persons with Disabilities, 5 EUR. J. DisABILITY RES. 249 (2011); Dimopoulos, supra note 20, at 46-47 (calling the "basic form of guardianship" unsatisfactory and stating that it must be "replaced by a legal framework of both protection and support, which will be offered non-coercively and tailored to meet the needs of each person with intellectual disability"); Mental Disability Advocacy CTR. \& Ass'N OF SoC. AfFirmation of People with Mental Disabilities, OUt of Sight: Human Rights in Psychiatric Hospitals and Social CARE Institutions IN Croatia 12, 14, 57 (2011), available at http://www.mdac.info/sites/mdac.info/files/croatiareport2011 en.pdf (recommending that guardianship be abolished in Croatia, but then apparently limiting this recommendation to the abolishment of plenary guardianship); Dhanda, supra note 21, at 460-62 (arguing that guardianship is a result of prejudice and is inconsistent with Article 12 of the CRPD); Bach, supra note 30.

65. Salzman, Guardianship for Persons, supra note 35, at 311. For example, while Sweden does not have a system called "guardianship," its "administrator" system is effectively a guardianship system. Indeed, Herr describes the administrator system as essentially identical to guardianship except that the subject retains capacity to vote. See Herr, supra note 51. Yet, in a number of U.S. states, wards retain their right to vote. See Sally Balch Hurme \& Paul S. Appelbaum, Defining and Assessing Capacity to Vote: The Effect of Mental Impairment on the Rights of Voters, 38 MCGEORGE L. REV. 931, 950-57 (2007). 
the state in providing or facilitating that support. This recognition is consistent with current understandings of the challenges faced by persons with such disabilities. While individuals with cognitive and intellectual disabilities tend to have preferences as to their daily living arrangements, they may need extensive support to understand the options they have relative to those preferences and to understand how to effectuate their wishes. ${ }^{66}$ For example, a study of adults with learning disabilities being cared for by elderly caregivers found that it was difficult for some participants to consider and talk about housing arrangements if their parents died or became too ill. ${ }^{67}$ In part, the need for additional support reflects such individuals' underlying disability. It also, however, may reflect the fact that individuals with ID often have little experience making important life decisions for themselves because they have been given few opportunities to do so. ${ }^{68}$

The concept of supported decision-making is therefore appealing from multiple perspectives. From a civil rights perspective, it recognizes the personhood of persons with cognitive and intellectual disabilities and avoids stripping them of their fundamental freedoms. It is also consistent with the CRPD's call for states to provide access to the support that persons with disabilities "may require in exercising their legal capacity." ${ }^{169}$ From a disability rights perspective, the supported decisionmaking model is consistent with the social model of disability that sees disability as socially constructed and seeks to avoid the use of disabling labels such as "incompetent." Adoption of supported decision-making has been described as presenting "an opportunity to re-imagine the disabled legal subject" $" 70$ and may thus have political and symbolic value in and of itself. From a public health perspective, supported decisionmaking has the potential to improve the overall physical and psychological well-being of persons with cognitive and intellectual disabilities by creating a sense of empowerment, which in turn has been linked to positive health outcomes. In short, a move toward supported

66. Laura Bowey \& Alex McGlaughlin, Adults with a Learning Disability Living with Elderly Carers Talk about Planning for the Future: Aspirations \& Concerns, 35 BRIT. J. SOC. WORK 1377, 1386 (discussing the "need for adults with learning disabilities to be given extensive support and accessible information in exploring options in order that they can make informed choices about their future plans").

67. Id.

68. LEVY \& RUBENSTEIN, supra note 2, at 106 (noting that many persons with ID "are frequently not allowed to participate in decision making to the extent of their abilities"); Ludlow, supra note 2, at 197 (discussing the experience of loss for persons with developmental disabilities and suggesting that decision-making is a skill that can be learned).

69. See CRPD, supra note 20.

70. See Carney, supra note 36 , at 62 . 
decision-making may have both symbolic and instrumental value from a variety of perspectives. ${ }^{71}$

Despite its appeal, however, the call for supported decision-making raises significant policy questions, as well as descriptive empirical ones. First and foremost, it raises concerns about whether supported decisionmaking mechanisms can in fact achieve the lofty goals set out for them and, if so, how. For example, how can supporters effectively empower individuals with cognitive and intellectual disabilities to make decisions on their own behalf? How can supported decision-making systems ensure that they are truly voluntary and minimize the risk that they will subject persons with disabilities to new forms of coercion? In advocating for a move toward supported decision-making as an alternative to guardianship, Salzman has described supported decisionmaking models as having four primary characteristics: (1) the individual retains legal decision-making authority; (2) the relationship is freely entered into and can be terminated at will; (3) the individual actively participates in decision-making; and (4) decisions made with support are generally legally enforceable. ${ }^{72}$ This is, however, a normative description, and the question is whether it is empirically supported. Accordingly, Part III explores the evidence base for supported decisionmaking.

\section{THE EVIDENCE BASE FOR SUPPORTED DECISION-MAKING}

Perhaps surprisingly for a model in its second decade of development, there is little empirical evidence directly evaluating supported decision-making. Indeed, a number of recent discussions of supported decision-making note the lack of, and need for, empirical evidence that evaluates the different models of supported decisionmaking. ${ }^{73}$ Even articles that provide extensive discussions of the benefits

71. Cf. id. (suggesting that the move toward supported decision-making should be "highly ... commended on the basis of its symbolic significance" despite concerns that it may be in reality "de facto" guardianship) (emphasis in original).

72. Salzman, Guardianship for Persons, supra note 35, at 306-07.

73. See, e.g., Nidus, A Study of Personal Planning In British Columbia: REPRESENTATION AGREEMENTS WITH STANDARD POWERS 4 (2010), available at www.nidus.ca/PDFs/Nidus_Research_RA7_InAction.pdf ("There is a need for qualitative research to gain insight into the motivations and experiences of adults and their personal supporters with respect to the making and using of Representation Agreements with standard powers."); OfFICE OF THE PUB. ADVOCATE, supra note 63, at 8 ("Supported decision-making is presently quite loosely defined and articulated and there is very little material in literature or policy to draw on."); Wendy Harrison, Representation Agreements in British Columbia: Who is Using Them and Why? 2 (unpublished M.A. thesis, Simon Fraser University) (2008) ("To date, there has been no research undertaken in British Columbia examining the use of representation agreements."); Improving Supported Decision Making, VICTORIAN L. REFORM COMM'N 
and potential drawbacks of supported or co-decision-making provide little or no empirical support for their claims. ${ }^{74}$ This dearth of empirical literature is not unique to supported decision-making; there is also surprisingly little evaluative empirical literature on guardianship. ${ }^{75}$ Nevertheless, this lack of evidence is unfortunate not only because it means that we do not know whether supported decision-making is achieving its goals but also because it makes it difficult to develop and support effective evidence-based supported decision-making practices. In this Part, we therefore identify some of the potential contexts in which supported decision-making could and should be evaluated moving forward, noting the existing research and incorporating additional findings. The overarching questions are whether supported decisionmaking achieves its goals and whether it achieves such goals better than existing practices such as guardianship models.

In discussing the existing and needed research on supported decision-making, we find it helpful to distinguish between two key types of research questions. First, there are questions related to the utilization of supported decision-making (e.g., what are the demographic characteristics of those involved, and how common are such arrangements?). Second, there are questions about the outcomes of the supported decision-making process. Outcomes, in turn, can be divided into process-oriented outcomes on the one hand and substantive outcomes on the other, a distinction that serves as a useful tool in identifying existing research and in prompting further research. ${ }^{76}$

(June 1, 2011), http://www.lawreform.vic.gov.au/journal-articles/improving-supporteddecision-making (calling for submissions providing opinions and evidence as to benefits of supported or co-decision making); Pathare \& Shields, supra note 34, at 27, 30 (exploring research on supported decision-making-very broadly defined-for persons with mental illness and concluding that the research on supported decision-making is limited and that more research is "urgently needed").

74. See e.g., Devi et al., supra note 64; Sarah Burningham, Developments in Canadian Adult Guardianship and Co-Decision-Making Law, 18 DALHOUSIE J. LEGAL STUD. 119 (2009).

75. See Linda S. Whitton \& Lawrence A. Frolik, Surrogate Decision-Making Standards for Guardians: Theory and Reality, 2012 UTAH L. REV. 1491 (2012) (describing the lack of empirical literature on how guardians make decisions on behalf of wards); TEASTER ET AL., supra note 12, at 15 (noting that there is little empirical literature on guardianship provisions); see also CTR. FOR ELDERS \& THE COURTS, NAT'L CTR. FOR State Courts, adult Guardianship Court Data and Issues: Results From an ONLINE SURVEY 8 (2010), available at http://www.guardianship.org/reports/ Guardianship_Survey_Report.pdf ("Recent attempts at collecting state data on guardianships have demonstrated the absence of meaningful data.").

76. See Nina A. Kohn \& Jeremy A. Blumenthal, Designating Health Care Decisionmakers for Patients Without Advance Directives: A Psychological Critique, 42 GA. L. REV. 979, 1008-10 (2008) (making the distinction and discussing tradeoffs 


\section{A. Research on Supported Decision-Making Utilization}

Understanding how supported decision-making systems are being utilized has the potential to help identify those populations that might benefit from or desire decision-making support, and thus those populations to whom resources and services related to supported decision-making might be most profitably directed. Understanding the gaps in knowledge about supported decision-making utilization can also serve to target much-needed further empirical research. Accordingly, in this Section we identify research, and, more importantly, gaps in research, on the rate at which existing supported decision-making systems are utilized, and the demographic composition of both the individuals receiving decision-making support (i.e., "principals") and those appointed to provide that support (i.e., "supporters").

\section{Frequency of Utilization}

One fundamental question about supported decision-making is how often individuals make use of supported decision-making arrangements where they are currently available. Whether because of differences in actual utilization, reporting, or the populations making use of such arrangements, estimates of such rates vary substantially. For instance, Surtees identified a small number of cases filed under Saskatchewan's Adult Guardianship and Co-decision-making Act (2001), about 500 in approximately a seven-year period. ${ }^{77} \mathrm{He}$ found that more than 90 percent of applications seeking some sort of support under the Act asked for a guardian to be appointed to help with decisions regarding person or property; only about seven percent (30/446) applied to have a codecision-maker appointed. ${ }^{78}$ By contrast, a review of Representation Agreements in British Columbia conducted by Nidus Personal Planning Resource Centre and Registry ${ }^{79}$ identified far more Agreements over a three-and-a-half-year period: almost 1,000 Agreements requesting a representative to help with standard decisions. ${ }^{80}$

between process outcomes and substantive outcomes in the context of default surrogate statutes).

77. Surtees, supra note 52, at 92 . Surtees noted that the cases he reviewed did not include 83 closed cases placed in storage that he was unable to access. Id.

78. Id. Surtees did not report further individuating information about the cases. Id.

79. Nidus is a nonprofit organization that provides training and assistance to those interested in forming such agreements. See supra note 38.

80. Id. (identifying 989 Representation Agreements with standard powers). Under the relevant Act, "standard powers" can include personal care, routine management of financial affairs, or certain health care decisions. Non-standard (or Section 9) Agreements grant broader authority to the representative, especially in the health-care context, and include the authority to override some decisions by the principal. 
Neither study, however, allows for a good estimate of the rate of uptake among those subsets of the population for which they are touted as advantageous. This is because neither study identified the population out of which these counts were made, i.e., whether 500 or 1,000 represented a large proportion of those who might be eligible for assistance under the relevant legislation. The Nidus study also did not compare the rate of those choosing standard Agreements with the rate of those selecting non-standard ones, perhaps because this number is not clear either. One unpublished study (a master's thesis by Harrison) identified approximately 600 individuals in British Columbia who had entered in Section 9 (non-standard) Agreements as of mid-2007, with a final sample of 93 individuals. ${ }^{81}$

Thus, it is difficult to determine to what extent persons with cognitive and intellectual disabilities would utilize supported decisionmaking if made available in the United States. Moreover, even if we were able to predict what proportion of those who would otherwise be subject to guardianship would likely be diverted to a supported decisionmaking alternative, we would have difficulty predicting the number of persons likely affected. One reason that it is hard to predict is that it is unknown how many people in the United States are subject to guardianship. Researchers have estimated that approximately 1.5 million people in the United States are subject to guardianship at any given time. $^{82}$ However, the actual numbers are unknown, in part because the guardianship process is state-specific and many states fail to provide the types of records that would enable a national assessment. ${ }^{83}$

81. Harrison, supra note 73 , at 22-25.

82. See Brenda K. Uekert \& Richard Van Duizend, Nat'L Ctr. for State Courts, Adult Guardianships: A "Best Guess" National Estimate and the MOMENTUM FOR REFORM 107, 108-09 (2011), available at http://www.guardianship.org/ reports/Uekert_Van_Duizend_Adult_Guardianships.pdf (estimating that there are 1.5 million guardianships in the United States but suggesting that the actual number could range from 1 to 3 million); Dorothy Squatrito Millar \& Adelle Renzaglia, Factors Affecting Guardianship Practices for Young Adults with Disabilities, 68 EXCEPTIONAL CHILDREN 465 (2002) (estimating 1.25 million adults under guardianship in the United States); TEASTER ET AL., supra note 12 (discussing different estimates and the overall lack of evidence on the frequency of guardianship); ERICA F. WOOD, AM. BAR ASS'N COMM'N ON LAW \& Aging FOR THE Nat'l CTR. ON Elder Abuse, State-Level adult GUARDIANSHIP DATA: AN EXPLORATORY STUDY 11 (2006) (discussing different estimates and the overall lack of good numbers on the frequency of guardianship). That number may have increased over the past 25 years. See TEASTER ET AL., supra note 12, at 4 (noting a 1988 Associated Press estimate putting the number at 400,000).

83. WOOD, supra note 82, at 33-34 (finding that nearly two-thirds of state court administrative offices that responded to a national survey on guardianship did not keep separate data on guardianship cases, and even those that did tended to limit the separate data to that on frequency of filings and dispositions). 
Another reason that it is hard to predict the number of persons who could be diverted from guardianship into supported decision-making is that it is also unknown what portion of persons subject to guardianship are persons with ID - the population most frequently discussed as having the potential to benefit from supported decision-making. ${ }^{84}$ However, the United States likely has a sizeable population of persons with ID subject to guardianship. A 2005 survey of public guardianship programs found that those programs providing researchers with adequate information about their wards reported that more than half of such wards had a primary diagnosis of either developmental disability or mental retardation. ${ }^{85}$ The study reported that this finding represented a shift in the guardianship system away from an older adult population to a

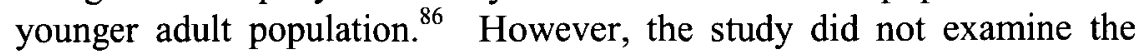
diagnoses of wards with private guardians, and it is certainly possible that there are significant differences in the diagnoses of those in private guardianship relationships. ${ }^{87}$

\section{Demographics of Principals}

Another fundamental question about supported decision-making is what groups of people tend to utilize such arrangements. Unfortunately, there are also few data on the demographic composition of those who enter into supported decision-making relationships as principals. Data from British Columbia ${ }^{88}$ suggest that women are more likely to be principals than are men. Nidus's figures indicate that, when it comes to Representation Agreements involving "standard" provisions, there was a 55 percent to 45 percent disparity between women and men. ${ }^{89}$ Harrison's smaller study suggests, however, that the disparity is even greater when non-standard provisions are involved; the breakdown was

84. See id. at 34 (stating that it is unknown what percentage of wards have "mental retardation" or "developmental disabilities").

85. See TEASTER ET AL., supra note 12, at 66 . Among them, the responding groups had served over 24,000 wards. This figure is based on adding up the figures provided in the "extent of guardianship tables" from Section IV of the report. See id. $\S$ IV.

86. See id. at 95 .

87. It is also unknown what percentage of guardians are public guardians, as opposed to family members, friends, or other third parties. See WoOD, supra note 82, at 34 (lamenting this lack of information). It can be reasonably assumed, however, that most guardians are not public guardians. $C f$. id. at 12 (referring to a study of guardianships in the San Francisco Probate Court that found 29\% of guardians appointed were public guardians).

88. Much of the data discussed herein comes from British Columbia-based studies. This is simply due to a lack of empirical studies from other jurisdictions.

89. NIDUS, supra note 73 , at 2. 
approximately $2: 1 .^{90}$ In terms of age, some evidence suggests a bimodal distribution of those who engage representatives, at least ones for Agreements with "standard" provisions. In particular, adults in their 20 s were the largest age category of those making such selections (23 percent), with those in their $80 \mathrm{~s}$ at just under 20 percent. $^{91}$ Together, adults over 70 made up about 40 percent of those selecting representatives, while those over 60 made up about 50 percent. ${ }^{92}$ Harrison's study suggests, however, that those selecting Agreements involving non-standard provisions tend to be older than those selecting Agreements with standard provisions. ${ }^{93}$ The Harrison study also found that principals involved with non-standard Agreements tended to be married, relatively well-off financially, and relatively educated. ${ }^{94}$

Nevertheless, because supported decision-making is often seen as particularly likely to benefit those with ID, a fundamental concern with these demographic data is that it is unclear how representative they are of individuals with ID. As noted, for instance, Surtees did not distinguish among the cases he reviewed, and it is not evident whether Harrison's sample included persons with ID, ${ }^{95}$ nor is it clear from the Nidus study that a significant portion (or even any) of the 989 individuals had some form of ID. Thus, if these samples are not representative, then it is harder to draw inferences from the research. That is, on the one hand, finding that individuals without ID make use of supported decisionmaking would only reinforce the idea that this approach could promote inclusion of persons with ID by offering them the same supports that are used by a broader population. On the other hand, that same finding would give little insight into the important question of the extent to which persons with ID make use of supported decision-making or how supported decision-making can help persons with ID. Thus, further research addressing these basic questions of who uses supported decision-making, and when, is of substantial importance.

90. Harrison, supra note 73 , at 30 (noting a $62.5 \%$ to $37.5 \%$ women-to-men split).

91. NidUS, supra note 73 , at 2 .

92. Id. This may be consistent with findings that elderly persons seem to prefer group decision-making by multiple family members. See Suzanne B. Yellen et al., Communication About Advance Directives: Are Patients Sharing Information With Physicians?, 1 CAMBridge Q. HealthCARE ETHICs 377 (1992).

93. Harrison, supra note 73 , at 30 .

94. Id. at 30-32.

95. Id. at 36 tbl.1 (setting forth diagnoses of principals and not listing either ID or developmental disability; however, persons with ID may have been included in other categories-e.g., the category of "Alzheimer's or other dementia"). 


\section{Demographics of Supporters}

Just as it is important to understand who elects to receive support, in order to understand how supported decision-making actually works, it is critical to understand who tends to provide that support. Unfortunately, there are also little data available as to those selected to be supporters. We know that, in the context of surrogate decision-making for health care, patients who execute advance directives (documents that allow someone else to make health care decisions on their behalf in the event that they lose capacity to make those decisions for themselves) overwhelmingly select relatives as proxies or surrogates. ${ }^{96}$ Some evidence suggests a similar trend for the selection of supporters in supported decision-making arrangements. Specifically, close to 90 percent of Agreements in British Columbia appointed a parent, child, sibling, spouse, or other family member as a representative. ${ }^{97}$ Similar to surrogate selection, immediate family took precedence: less than ten percent of representatives were "other family members"- the same percentage as "friends." Similar results came from the small sample of non-standard (Section 9) Agreements in British Columbia: over 80 percent of individuals selected a spouse ( 29 percent) or other family member (54 percent) as the representative, with 17 percent appointing a friend. ${ }^{99}$

Non-relatives, however, appear to be frequently selected as alternative representatives in the British Columbia system, at least for standard Representation Agreements. In this context, the proportion of non-immediate family members (others and friends) rises to about 40 percent. Interestingly, however, when monitors are selected-i.e., someone to oversee the representative - these proportions reverse. Approximately 30 percent of monitors are "other family members" and an equal percentage of monitors are "friends," perhaps suggesting the desire to have a more objective level of "checks and balances."100

The existing information suggests that supported decision-making is likely to occur primarily within families and thus be subject to the attendant family dynamics-dynamics which may or may not be

96. See Kohn \& Blumenthal, supra note 76, at 990 \& n.55.

97. NiDUS, supra note 73 , at 3 . Thus, the representative is probably likely to be the same person who would be selected as a guardian if a guardianship had been pursued instead. Where a guardianship is pursued over a person with ID, the petitioner is typically the allegedly incapacitated person's parent and, in particular, his or her mother. See Millar, supra note 13, at 379 (finding that petitions for guardianship over persons with ID are typically filed by family members, usually mothers).

98. NiDus, supra note 73 , at 3 .

99. Harrison, supra note 73 , at 69 .

100. Nidus, supra note 73 , at 3 . 
empowering. However, more information on the identities of supporters and their relationships to principals is critical if we are to understand how supporters are selected and the relational context in which supported decision-making is likely to occur.

\section{Impact of Race and Ethnicity}

None of the empirical studies we identified as discussing supported decision-making addressed any racial demographics. However, such information would be valuable to those evaluating supported decisionmaking practices because race and ethnicity may affect whether people engage in supported decision-making and who is selected as a supporter. Specifically, racial and ethnic differences exist in patients' approaches to medical decision-making, with members of some groups preferring a more distributed, non-patient-centered approach. ${ }^{101}$ Members of such groups may be more willing than average to engage in supported decision-making in situations in which the principal would otherwise be expected to make decisions independently, but perhaps less likely than average to see supported decision-making as a desirable alternative to guardianship. Racial and socio-economic status differences also appear in the likelihood of possessing advance directives generally, with white, higher socio-economic status, and more educated individuals more likely to execute advance directives. ${ }^{102}$ Thus, some persons belonging to certain racial groups and those with higher socio-economic status may similarly be more likely to enter into supported decision-making arrangements. However, from existing studies, we cannot ascertain whether such differences exist.

\section{B. Research on Supported Decision-Making Outcomes}

The most important questions related to supported decision-making are those related to the ability of supported decision-making systems to achieve their goals. In this Section, we therefore analyze the meager existing research on the effect and impact of supported decision-making systems and identify key gaps in that research. To do so, we divide the research into two broad categories: (1) research that provides insight into the process of supported decision-making (e.g., the types of

101. See, e.g., Leslie J. Blackhall et al., Ethnicity and Attitudes Toward Patient Autonomy, 274 JAMA 820, 824 (1995).

102. See Rebecca S. Allen \& John L. Shuster, Jr., The Role of Proxies in Treatment Decisions: Evaluating Functional Capacity to Consent to End-of-Life Treatments Within a Family Context, 20 BEHAV. SCI. \& L. 235, 239 (2002); Sarah Forbes et al., End-of-Life Decision-Making for Nursing Home Residents with Dementia, 32 J. NURSING SCHOLARSHIP 251, 252 (2000). 
discussions that occur in supported decision-making relationships); and (2) research that provides insight into the substantive outcomes of those processes (e.g., the decisions that are reached).

\section{Process Outcomes}

There is a growing literature addressing how supported decisionmaking should work; ${ }^{103}$ there is far less literature on how it in fact does work. $^{104}$ Harrison's unpublished thesis examining Representation Agreement arrangements in British Columbia ${ }^{105}$ is one of the more thorough descriptive accounts. Harrison found that over 80 percent of individuals she studied spoke with their representative at least several times a week and that nearly half spoke daily. ${ }^{106}$ Harrison also inquired into some of the substance of these discussions, focusing on the health care aspects of the discussions. Among other findings, Harrison discovered that about half of the individuals studied had only general discussions with their representatives, but others had discussed specific issues such as life support, organ donation, pain control, or do-notresuscitate orders. ${ }^{107}$ Harrison also found that most of her subjects had discussed "their feelings and values about the types of situations that could arise and what impact that should have on how their representative made treatment decisions." 108 When principals and supporters do discuss values, there may be an increased likelihood that supporters will come to understand, agree with, and share the principal's values, and thus be more likely to effectuate the principal's preferences. ${ }^{109}$ Accordingly, Harrison's findings-especially if corroborated by further supported

103. See generally, e.g., Salzman, Guardianship for Persons, supra note 35; Robert M. Gordon, The Emergence of Assisted (Supported) Decision-Making in the Canadian Law of Adult Guardianship and Substitute Decision-Making, 23 INT'L J. L. \& PSYCHIATRY 61 (2000).

104. Some research presents case studies of individuals selecting supported decisionmaking, e.g., Gordon, supra note 103, at 64-65; however, the actual decision-making process is not described in any detail.

105. See Harrison, supra note 73.

106. Id. at 71 tbl.25.

107. Id. at 77 tbl.28.

108. Id. at 78 .

109. Elsewhere, two of us have suggested that surrogate health care decision-makers be selected based on degree of shared values in order to maximize the likelihood of proxies making the treatment decision that matches what a patient would choose. See Kohn \& Blumenthal, supra note 76, at 1011-12 (suggesting this as an alternative to selection based on familial proximity). But see Carol Matheis-Kraft \& Karen A. Roberto, Influences of a Values Discussion on Congruence Between Elderly Women and Their Families on Critical Health Care Decisions, 9(4) J. WomEN \& AGNG 5, 15 (1997) (noting that prior discussion by competent patients and their proxies rarely led to improved proxy accuracy, but noting methodological limitations in their study). 
decision-making research confirming that such discussion occurs regularly-provide reason to be optimistic that supported decisionmaking will protect individuals' preferences.

Although there is a literature base, albeit limited, on the types of discussions that occur in supported decision-making, we were unable to identify any research on the internal dynamics of those discussions. Even the Harrison study did not discuss the dynamics of particular decisions. This absence presents a significant problem for evaluating the impact and efficacy of supported decision-making.

One of the primary worries, even for those advocating supported decision-making, is the potential for coercion or other inappropriate influence by a representative or supporter. ${ }^{110}$ Exploitation and abuse certainly occur in guardianship context (although it is unclear how frequently), ${ }^{111}$ and supported decision-making arrangements create new opportunities for abuse. Indeed, when we turn to more informal arrangements such as supported decision-making, which may occur in private and with less accountability, the potential for financial or other abuse likely increases. However, data do not seem available on the incidence of such abuse in the supported decision-making context.

Undue influence can occur even if the supporter or representative may not deliberately set out to take advantage of or influence the principal decision-maker, leading him or her to a desired outcome. Through particular issue-framing, inaccurate assessment of the principal's preferences, or simple conversational style, a discussion may easily be led one way or another to an outcome that does not accurately reflect the principal's preferences. Both kinds of undue influence, moreover, might be facilitated by third parties mistakenly assuming that supporters have decisional power and thus erroneously elevating supporters' opinions or wishes above those of principal. ${ }^{112}$

In addition to undue influence resulting from deliberate coercion or unconscious influence by the supporter, undue influence may also

110. See Office of The Pub. Advocate, supra note 63, at 25 ("Supported decisionmaking does open up the possibility of conflict, undue influence, abuse and exploitation."); Salzman, Guardianship for Persons, supra note 35, at 309 (noting the difficulty of assisting someone in making a decision "without inappropriately influencing her final decision" and noting importance of protecting decision-maker from being "harmed or exploited within, or as a result of, the support arrangement"); Gordon, supra note 103, at 75 (noting potential for abuse or undue influence).

111. U.S. Gov'T ACCOUNTABILITY OFFICE, GAO-10-1046, CASES OF FinanCIAL EXPlOITATION, NEGLECT, AND ABUSE OF SENIORS 5 (2010) (identifying "hundreds of allegations" of abuse of seniors under guardianship as well as confirming cases); Naomi Karp \& Erica F. Wood, Guardianship Monitoring: A National Survey of Court Practices, 37 STETSON L. REv. 143, 150 (2007).

112. Cf. Carney, supra note 36 (discussing this possibility). 
originate in deliberate deference by the principal decision-maker. That is, some research on surrogate health care decision-making suggests that older adults tend to prefer trusting a surrogate decision-maker rather than expressing a treatment preference themselves. ${ }^{113}$ To the extent this deference occurs in the supported decision-making context, a substantial part of the model's goals would be subverted. Unfortunately, however, the little evidence regarding the dynamics of the supported decisionmaking process does not allow investigation of whether and how this might occur. Evidence is also needed regarding the incidence of undue influence, coercion, or abuse in these arrangements, as well as regarding what risk factors exist that might encourage such influence and what structures might help to discourage it.

\section{Substantive Outcomes}

In assessing supported decision-making, perhaps the most important questions, and the most difficult, are: (1) how to ensure that a decision arrived at through supported decision-making truly expresses and effectuates the wishes or preferences of the person with intellectual or cognitive disability; and (2) whether such decisions are more beneficial to the person with a disability compared to decisions made using other approaches (e.g., decisions made without support, by a guardian, or by another form of surrogate decision-maker).

\section{a. Psychological Impacts on Principals}

There is reason to suspect that the interactive, dynamic results of the supported decision-making process may have beneficial psychological consequences for the participants, especially persons with ID. For instance, there is some evidence that the guardianship model can lead to feelings of disempowerment and loss of control on the principal's part because he or she is not involved in the relevant decision-making. ${ }^{114} \mathrm{~A}$ more shared process where the supporters or representatives are generally, if not explicitly, seen as assisting ${ }^{115}$ may ameliorate this perception. ${ }^{116}$ Similarly, under the guardianship model, relegating an

113. Steven H. Miles et al., Advance End of Life Treatment Planning: A Research Review, 156 ARCH. INTERNAL MED. 1062, 1063 (1996).

114. See Teaster, supra note 25 , at 348 (in a qualitative study interviewing 13 wards of public guardians, finding such sentiments common); Salzman, Rethinking Guardianship, supra note 23, at 163 (describing guardianship as creating "constructive isolation").

115. E.g., Gordon, supra note 103, at 62-63.

116. See Nina A. Kohn, Elder Empowerment as a Strategy for Curbing the Hidden Abuses of Durable Powers of Attorney, 59 RUTGERS L. REV. 1, 44 (2006) (identifying 
individual to "ward" status, making clear that another party has been appointed explicitly to make that individual's decisions, may stigmatize the individual not only in his or her own eyes but also in the eyes of others. The supported decision-making model might counter such perceptions by highlighting that, even with some reduced capacity, an individual with cognitive or intellectual disabilities is nevertheless capable of engaging in, managing, or directing self-relevant decisions in a number of contexts.

As with some of the previous discussion, however, this is primarily speculation. We have insufficient data in the specific supported decision-making context to know whether such benefits are actually realized in supported decision-making. Given the often negative and harmful stereotypes about persons with cognitive and intellectual disabilities, however, and that the desire to address such stereotypes is one reason for the push toward supported decision-making, this too seems a valuable avenue of research.

There is also reason to suspect that supported decision-making may have a positive impact on the cognitive and emotional health of persons with cognitive and intellectual disabilities. Again, Harrison found that principals tended to speak with their representatives at least several times per week (though the substance of those discussions is not evident). The more that such discussions in fact reflected decision-making processes, especially active decision-making by the principal, then the more cognitively active the principal may have been and, as a result, the more cognitively healthy. ${ }^{117}$ Moreover, to the extent that the supported decision-making relationship enhances the person's sense of connectedness with others, this too may have psychological benefits. ${ }^{118}$

Unfortunately, it is also possible that supported decision-making could have a negative impact on principals' psychological well-being. To the extent that such relations do facilitate undue influence or

psychological studies suggesting circumstances that can lead to a benefit in the principal's sense of control when assisted in making decisions).

117. Cf. Michael Valenzuela \& Perminder Sachdev, Can Cognitive Exercise Prevent the Onset of Dementia? Systematic Review of Randomized Clinical Trials with Longitudinal Follow-Up, 17 AM. J. GERIATRIC PSYCHIATRY 179, 185-86 (2009) (noting that "cognitive exercise may be an effective strategy for delaying the onset of cognitive impairment in older adults").

118. See Sarah H. Ailey et al., Evaluating an Interpersonal Model of Depression Among Adults with Down Syndrome, 20 RES. \& THEORY FOR NURSING PRACTICE: AN INT'L J. 229, 241-42 (2006) (reporting that loneliness and social isolation are common among persons with Down syndrome and/or developmental disabilities and that these may increase such individuals' risk for depression); BIGBY, supra note 3, at 116-19 (discussing the importance of social networks for the psychological well-being of persons with ID). 
exploitation, as some fear, they may undermine individuals' senses of control and well-being. Similar results might occur if entering into a supported decision-making relationship is not voluntary but rather something foisted on the person with a disability, as some have warned may occur. ${ }^{119}$

\section{b. Congruency Between Wishes and Decisions}

As the Office of the Public Advocate in Victoria, Australia, aptly explained in its 2009 Discussion Paper on supported decision-making, "[L]iterature on supported decision-making speaks of discerning the will and preferences of the person and of assisting the person to make and communicate preferences and choices. There is often the implication that the if [sic] the person's will, preferences and wishes are expressed, they are actually making the decision." ${ }^{20}$ Yet, as the report went on to explain:

A key issue in supported decision-making is how and whether a person can be supported to make their own decisions by assisting them with those elements of decision-making where they have difficulty. How does the group decide whether the decision is a valid decision? Can a person be assisted through information, emotional support or in some other way to make their own decisions if they do not have, for example, an appreciation of the significance of the decision they are making or a reasonably consistent set of values? ${ }^{121}$

In other words, there is a potentially unavoidable paradox in acknowledging that a person has diminished decision-making capacity but maintaining that he or she is nevertheless capable of meaningfully contributing to decision-making discussions and that the decisions that result from such discussions reflect his or her wishes. Similarly, how does one avoid a similar paradox in maintaining that a person can make that decision with assistance unless one is confident that person has a "consistent set of values" to ground such a decision?

Determining whether supported decision-making helps persons achieve their wishes is further complicated by the fact that there are multiple ways of defining those wishes, and it may not be clear-even to the person with the cognitive or intellectual disability - what those wishes are. For example, people in general have significant difficulty with "affective forecasting," that is, with predicting both their own and

119. See Carney, supra note 36 , at 62 .

120. OfFICE OF THE PUB. ADVOCATE, supra note 63, at 23.

121. Id. 
others' future emotional states, reactions, and preferences. ${ }^{122}$ Moreover, a person may have preferences for certain procedures either in addition to, or even in lieu of, preferences for certain outcomes of those procedures. That is, individuals sometimes prefer that decisions be made via some particular process; if decisions are in fact made via that process, then the individuals are less concerned about the actual outcome. ${ }^{123}$ In such cases, there is the possibility that a supported decision-making system will yield a process that is consistent with principals' wishes without yielding a substantive outcome that is consistent with their wishes. The crucial question then becomes whether the system should be considered to be effectuating their wishes. Some might argue that establishing that supported decision-making provides a satisfactory process for these persons might be as, if not more, important than addressing the success of the decisions that emerge. However, allowing process to be the sole criterion for evaluating the success of such decision-making could result in treating the process as a success even when it results in decisions that the principal perceives to be (or that objectively are) substantively harmful.

\section{c. Quality of Decisions Made}

We found no research evaluating the quality of decisions reached using supported decision-making. This lack of research may reflect the fact that it is very difficult to evaluate decision quality. Evaluating a particular decision (whether made through supported decision-making or

122. Jeremy A. Blumenthal, Law and the Emotions: The Problems of Affective Forecasting, 80 IND. L.J. 155, 217-22 (2005) (noting implications of affective forecasting research for euthanasia and advance directives). For instance, people do not consider the possibility of inaccurate assessment of their own preferences or the likelihood that their preferences may change based on future circumstances. As two of us have noted elsewhere, such difficulties can call into question the accuracy or value of decisions that are made by simply imagining what a future situation will be like. See Kohn \& Blumenthal, supra note 76 , at 995 . Studies that ask prospective decision-makers to speculate about future preferences may mis-state their findings to the extent that those difficulties are not considered. More important, actual decisions (supported or not) that do not consider these possibilities may inaccurately predict preferences at some later time.

123. This point again draws on research in advance directive and surrogate decisionmaking contexts. See Kohn \& Blumenthal, supra note 76, at 1007-10; Dallas M. High, Standards for Surrogate Decision-Making: What the Elderly Want, 17 J. LONG TERM CARE ADMIN. 8, 11 (1989) (elders seemed more interested in whom to select as a surrogate than in which standard the surrogate would use for making decisions about them); Angela Fagerlin et al., The Use of Advance Directives in End-of-Life DecisionMaking: Problems and Possibilities, 46 AM. BeHAV. ScIENTIST 268, 278 (2002) (some decision-makers seem "less concerned with the specific treatment decisions that are made than about having the decisions made by someone they trust"). 
otherwise) involves establishing a criterion against which the decision can be measured. Thus, both policy- and data-driven research will be necessary in developing appropriate criteria by which to evaluate decisions obtained through supported decision-making processes. The most obvious standards include whether a decision increases an individual's welfare in some way. For example, evaluators might ask whether the decision maintains the individual's autonomy or capacity for self-determination, allows him or her to pursue work, leads to profitable management of his or her finances, or avoids detrimental health outcomes.

In evaluating decision-making quality, it is important to recognize that the goal of reaching decisions that are in the best interest of the person with a disability may come into tension with other values that supported decision-making processes seek to promote, such as autonomy, self-determination, and dignity. ${ }^{124}$ For example, allowing or even encouraging a person with cognitive or intellectual disability to "learn from mistakes" may undermine efforts to protect that person from harmful outcomes. Ultimately, the decision as to how to balance such tensions is one for legislative bodies or, if they decline to do so, supporters. For example, legislation might permit a supporter not to acquiesce in a decision that might negatively affect a principal's estate (as in Saskatchewan) ${ }^{125}$ or that is not "reasonable" (as in British Columbia). ${ }^{126}$

In order to determine how best to address such tensions when they arise, it would be helpful to have empirical evidence on issues such as the extent to which such individuals truly might learn from their mistakes, ${ }^{127}$ the value they (or their supporters) may in fact attach to such personhood factors, and the likelihood that supporters will feel comfortable either allowing a decision that may be harmful, or "interfering" to redirect such a decision. ${ }^{128}$

Assessing the relative quality of decisions made using supported decision-making, moreover, will require more than simply determining whether it yields a beneficial or effective outcome. It will also require

124. "It is easy to say that a person has the right to make unwise decisions and that there is dignity in risk. . . It is less easy to determine whether the person understands the risks or can foresee the consequences of their decision," and thus who should make the decision. OfFICE OF THE PUB. Advocate, supra note 63, at 23.

125. See supra note 54 and accompanying text.

126. Representation Agreement Act, R.S.B.C., c. 405, pt. 3.16 (1996) (Can.) (setting forth the duties of the representative).

127. Cf. Jeremy A. Blumenthal, Emotional Paternalism, 35 FLA. ST. U. L. REV. 1, 7072 (2007) (suggesting the difficulty of learning from mistakes even for persons without cognitive or intellectual disabilities).

128. See Office of The Pub. Advocate, supra note 63, at 23. 
comparing the quality of decisions made using supported decisionmaking to those made by guardians. There are a number of ways such comparisons could be investigated. For instance, researchers could identify some decisions involved in actual supported decision-making interactions and then present the facts involved-facts regarding both the decision to be made and the individual and her circumstances-to a mock or actual guardian. That guardian would render a decision that could then be compared to the outcome of the actual supported decisionmaking decision. Other paradigms might be developed, of course, but the important point is that empirical research comparing supported decision-making and guardian decision-making will be useful in evaluating supported decision-making (as well as guardianship).

\section{d. Psychological Impact on, and of, Supporters}

Research on how supported decision-making affects those charged with providing support is also needed. Such research might follow a number of related avenues. First, we might investigate the effect of participation on these supporters. Providing care for others often takes a substantial physical and psychological toll on the caregivers. One plausible hypothesis is that any psychological benefits accruing from the supported decision-making model might benefit the supporter as well as the principal, perhaps because the actual participation might be less onerous than "traditional" methods of support or perhaps because of the actual dynamics of the supported decision-making interaction. Another hypothesis, however, might be that continually participating in another person's decision-making, without the "luxury" of one party or the other simply making the decision, creates more stress on the supporter than might otherwise occur or otherwise be expected. Similarly, we might study the effect of the supported decision-making process on supporters' psychological characteristics such as locus of control, perceived empowerment, etc.

A second line of research might explore who is the most helpful at assisting a person with a cognitive or intellectual disability to reach a beneficial decision ${ }^{129}$ - e.g., family members (of varying degrees of proximity), friends, health-care providers, or others. Such research would build upon evidence that in the surrogate decision-making context, different proxies are differentially accurate at discerning and effectuating a patient's preferences. ${ }^{130}$

129. Again, of course, whether the decision is in fact "beneficial" will depend on which criterion is used.

130. For instance, family members' decisions are somewhat more accurate than physicians' decisions, but there is little evidence of differences among family members. 
Third, advocates of supported decision-making often note the importance of training and of the development of safeguards, formal and informal, in curbing deliberate or unintentional influence or abuse. ${ }^{131}$ It would therefore be helpful to determine whether some supporters are more "trainable" than others and, if so, which ones. It would also be valuable to examine what types of safeguards, and what training in those safeguards, might be most effective in reducing inappropriate influence. Ultimately, the goal of such research would be to develop "adequate and appropriate safeguards" that neither become too burdensome ${ }^{132}$ nor fail to balance an individual's "freedom of action" with protection against "undue influence, abuse and exploitation." 133 As part of this research into safeguards, we might also recognize that, since third-party monitors may be an important type of safeguard, ${ }^{134}$ such research would ideally inquire into the conditions, if any, under which such monitors are effective and who is best suited to serve as a monitor.

\section{Effect of Individual Differences and Context on Outcomes}

In addition to the need for broad research on these supported decision-making topics, more focused study would be valuable. The impact and effectiveness of supported decision-making may vary by population and context, and such variations could potentially yield different specific policy recommendations.

\section{a. Individual Factors}

One useful approach might examine whether and to what extent supported decision-making outcomes vary by age and disability. As an initial matter, which, if any, of the findings sketched above (or that might result from further research) vary depending on the age of the person with a disability or the type of disability? For example, when might older persons with a certain disability act, feel, or decide differently from younger persons with that disability? Do such decisions, feelings, or actions differ by type of disability? Under what circumstances are older

See Kohn \& Blumenthal, supra note 76, at 999. Commentators have called for additional research in this context to determine whether non-family members are any better. Id. at 999-1000.

131. See, e.g., Salzman, Guardianship for Persons, supra note 35, at 310 (discussing the need for "adequate training of support personnel, monitors, and those acting as surrogate decision-makers").

132. Id.

133. OFFICE OF THE PUB. AdVOCATE, supra note 63, at 25.

134. See BACH \& KERZNER, supra note 32 , at 168 (recommending that monitors be included in supported decision-making processes). 
individuals, or those with different kinds of disabilities, perceived or treated differently, either by their supporters or representatives, by the public, or by the mental health or judicial systems? If supported decision-making leads to coercive discussion processes (whether intentional or not), or even abuse, does the incidence of such occurrences vary with the principal's age group or type of disability? Do any psychological benefits that accrue from the supported decision-making model accrue differently for older persons, or ones with different types disabilities, and, if so, why?

Other personal characteristics should also be investigated. Socioeconomic status, race, and education level often factor into health-related decision-making, especially in the proxy or surrogate contexts; ${ }^{135}$ such characteristics thus warrant consideration as part of future research on supported decision-making. Gender is also an important factor in a number of health-care decision-making contexts, and preliminary evidence suggests some small gender differences in supported decisionmaking-related areas as well. For instance, Harrison found slight differences in the reasons that men and women enter into Representation Agreements $^{136}$ and found that men and women may have different understandings or expectations of what their representatives will do to effectuate their preferences. ${ }^{137}$ The Nidus study indicated that women undertook a majority of the Agreements described (55 percent to men's 45 percent). ${ }^{138}$

A plethora of psychological personality traits might also be associated with differences in supported decision-making outcomes. One of the most relevant traits might be differences in perceptions of, or locus of, control. Studies seem to show that a more internal sense of control is associated with taking steps toward having an advance directive or other similar initiatives, ${ }^{139}$ which generates at least two research hypotheses: first, that those with an internal sense of control might be more likely to undertake a Representation Agreement or pursue another form of supported decision-making (and, similar to the point above, that those who choose not to engage in supported decision-

135. See supra notes 101-02 and accompanying text.

136. Harrison, supra note 73, at 64-65.

137. See id. at 95 .

138. NiDUS, supra note 73 , at 2 .

139. See generally Harrison, supra note 73, at 11-12; J. LaPuma et al., Advance Directives on Admission: Clinical Implications and Analysis of the Patient SelfDetermination Act of 1990, 266 JAMA 402 (1991); K.L. Rodriguez \& A.J. Young, Elderly Veterans' Beliefs Concerning Life-Sustaining Treatment and the Control of their End-of-Life Health and Health Care, 18 J. AGING \& HEALTH 686 (2006); C.B. Rosnick \& S.L. Reynolds, Thinking Ahead: Factors Associated with Executing Advance Directives, 15 J. AGING \& HEALTH 409 (2003). 
making would have a lower sense of control); and second, that the shared decision-making of the supported decision-making process might increase a principal's sense of control. Indeed, Harrison found that those who undertook Representation Agreements reported feeling a better sense of control over their futures. ${ }^{140}$ Both would seem positive outcomes, especially in light of findings that a higher sense of control can be physically and psychologically beneficial. ${ }^{141}$

\section{b. Contextual Factors}

Finally, just as capacity is generally recognized as varying by context and decision, ${ }^{142}$ the circumstances under which supported decision-making will be beneficial and effective likely also vary by context and decision-type. It would be impractical to suggest research into supported decision-making's effectiveness with regard to every different decision in which a person with intellectual or cognitive disability might be involved. As an initial matter, we might therefore focus on those contexts in which those persons might most commonly find themselves. Health-care and financial arrangements seem the most obvious and are, unsurprisingly, the primary focus of legislative responses to the decision-making challenges of persons with intellectual and cognitive disabilities. Nevertheless, as noted at the beginning of this article (and as recognized in some legislation), there is a wide variety of everyday decision-making for which persons with cognitive and intellectual disabilities might invite assistance, and supplemental research on these would be valuable too.

\section{IMPLICATIONS OF RESEARCH ON SHARED DECISION-MAKING}

The preceding Part suggested a discouraging dearth of empirical information as to how supported decision-making functions in practice and as to its outcomes. Fortunately, studies of related practices have the potential to provide some insight. In particular, research on shared decision-making in the health-care context is useful-with some

140. Harrison, supra note 73 , at 40.

141. See Kohn, supra note 116 , at $44-45$ (discussing such findings); Kohn \& Blumenthal, supra note 76, at 1010 ("Executing an advance directive and expressing one's desires as part of that process may also help instantiate a sense of control over one's life and treatment, which can be beneficial for an individual's mental and physical health."). But see Kohn, supra note 116, at 44-45 (acknowledging studies showing circumstances in which sense of control might not be beneficial).

142. See Office of THE PUB. Advocate, supra note 63, at 19; see also Lawrence A. Frolik \& Mary F. Radford, "Sufficient" Capacity: The Contrasting Capacity Requirements for Different Documents, 2 NAELA J. 303 (2006) (discussing the level of capacity required to execute different types of legal documents). 
important caveats-because this model shares some key attributes with supported decision-making.

Shared decision-making has been described as an interactive "process in which both the physician and patients participate in the treatment decision-making process," 143 involving deliberation to achieve agreement on a treatment choice. ${ }^{144}$ Although there has been little consensus on an overarching definition of shared decision-making, ${ }^{145}$ there appears to be fairly widespread agreement as to its central features. Shared decision-making involves both clinicians and patients sharing information and-to some extent-values, in the hope of assisting patients to make better decisions. ${ }^{146}$ Thus, shared decision-making is seen as a way to promote patient self-determination, the primary value that guides health care decision-making in the United States, ${ }^{147}$ while

143. Cathy A. Charles et al., Shared Treatment Decision Making: What Does It Mean To Physicians?, 21 J. CliniCAl ONCOLOGY 932, 932 (2003) [hereinafter Charles et al., Shared Treatment]; Isabelle Scholl et al., Measurement of Shared Decision Making-A Review of Instruments, 105 Z. EVID. FORTBILD. QUAL. GESUNDHEITWESEN (ZEFQ) 313 (2011).

144. Cathy Charles et al., Decision-Making in the Physician-Patient Encounter: Revisiting the Shared Treatment Decision-Making Model, 49 SoC. SCI. \& MED. 651, 656 (1999) [hereinafter Charles et al., Physician-Patient Encounter]; see also Charles et al., Shared Treatment, supra note 143, at 932 (discussing essential characteristics of shared decision-making, including need to share not only information but also the process of decision-making with patient). We recognize that, at times, the dyad may involve a health care professional other than a physician. However, the physician is typically the focus of this empirical literature and is typically the other authority regarding treatment decisions.

145. N. Moumjid et al., Shared Decision Making in the Medical Encounter: Are We All Talking About the Same Thing?, 27 MED. DECISION MAKING 539, 539 (2007) (noting lack of common definitions of shared decision-making and inconsistent definitions within articles). Charles et al. attribute the divergence in definitions or lack of conceptual clarity to differences in patient and physician roles, how and when each should be involved, and what should be shared. See Charles et al., Shared Treatment, supra note 143, at 932. Noting the "murkiness" in such definitions, Makoul and Clayman developed an integrative model building on existing conceptions of shared decision-making. See G. Makoul \& M.L. Clayman, An Integrative Model of Shared Decision Making in Medical Encounters, 60 PATIENT EdUC. \& COUNSELING 301 (2006). Their model identified essential elements (e.g., eliciting patient preferences and values, sharing physician knowledge and recommendations, making a decision) and ideal elements (e.g., presenting evidence, reaching mutual agreement) of shared decision-making, and noted general qualities (e.g., partnership, deliberation/negotiation). See id. at 305 tbl.3.

146. See Charles et al., Shared Treatment, supra note 143 (specifically defining shared decision-making by its four critical characteristics: involving at least two parties (physician and patient); both parties sharing information; both parties taking steps to reach consensus around the preferred option; and reaching mutual agreement); Makoul \& Clayman, supra note 145.

147. See, e.g., Cathy Charles et al., Shared Decision-Making in the Medical Encounter: What Does it Mean? (Or It Takes at Least Two to Tango), 44 Soc. ScI. \& MED. 681, 682 (1997). Consistent with this approach, decisions are seen as best madeultimately-by patients, with shared decision-making adding the concepts of partnership 
simultaneously promoting important clinical objectives, such as patientcentered care and evidence-based patient choice. ${ }^{148}$

Thus, shared decision-making is roughly analogous to supported decision-making in the sense that the former is a form of dyadic supported decision-making in which the physician (clinician) is the "supporter" of a patient making a health care related decision or decisions. However, shared decision-making is distinct from more general conceptions of the supported decision-making model in four key ways.

First, in shared decision-making, the "supporter" is the clinician. Accordingly, empirical research into shared decision-making focuses on this dyadic (clinician-patient) relationship, for the most part excluding contexts where more parties are involved. ${ }^{149}$ In supported decisionmaking, by contrast, the supporter is typically a family member or friend (or multiple such supporters). ${ }^{150}$ Second, shared decision-making does not involve a formally - or legally-appointed party to assist with decision-making, while supported decision-making does involve such a party. Third, shared decision-making focuses on medical or health-care decisions, and, thus, empirical research on it emphasizes those types of decisions. Supported decision-making, as discussed earlier, can be much broader than "only" medical decisions. It can, and is generally intended to, include financial, legal, daily, and other decisions. Fourth, much of the existing shared decision-making research has been with populations that are dissimilar to the populations that are typically described as having particular potential to benefit from supported decision-making (i.e., persons with cognitive and intellectual disabilities). Although research on shared decision-making has been conducted with a variety of

and deliberation to achieve, arguably, greater connection to the goal of informed consent. See, e.g., Simon N. Whitney et al., A Typology of Shared Decision Making, Informed Consent, and Simple Consent, 140 ANNALS INTERNAL MED. 54 (2003).

148. Whitney et al., supra note 147, at 54; Eleanor Herriman \& Jessica Cerretani, Shared Decision Making-Benefits and Technologies, 2 MEDICAL INFORMATICS REV. 1 (2007).

149. See Charles et al., Physician-Patient Encounter, supra note 144, at 657, 685. Some shared decision-making researchers have built on this point to emphasize concerns-which are also present in supported decision-making-regarding the possibility of undue influence and the importance of "checks and balances" to avoid "coalitions" forming that might influence a principal's decision-making. See J. Gabe et al., It Takes Three to Tango: A Framework for Understanding Patient Partnership in Pediatric Clinics, 59 Soc. SCI. \& MED. 1071 (2004).

150. Indeed, even in the shared decision-making context, such relationships may be more complex than a simple physician-patient dyad for many patients, especially those who are members of more vulnerable populations who may rely on family and natural supports or those with complex cases where multiple clinicians are involved. See R.K. Sharma et al., Family Understanding of Seriously-Ill Patient Preferences for Family Involvement in Decision Making, 26 J. GEN. INTERNAL MED. 881 (2011). 
populations (children, racial and ethnic minorities, as well as mental health patients) ${ }^{151}$ and in a variety of medical contexts (palliative care, breast cancer, and other clinical settings), ${ }^{152}$ it has not emphasized populations with cognitive or intellectual disabilities. Thus, research in each of these areas may have implications for supported decision-making models, but, at this point, perhaps only at a broad level. Although research on shared decision-making can be analogized to supported decision-making contexts, the analogy will be limited until further research is done.

Despite these differences, research on shared decision-making provides some helpful insight into supported decision-making practice and policy. One important contribution is that it suggests conditions under which supported decision-making might be considered appealing to principals. Specifically, research on shared decision-making suggests that the extent to which principals feel that support is valuable may vary based on the principal's age and on the type of decision being made. For instance, a recent study from the Netherlands examined the use of shared decision-making in medical (e.g., surgery or vaccination) and nonmedical (e.g., occupational healthcare, lifestyle decisions, diet, workrelated decisions, etc.) contexts, as well as patient preferences about shared decision-making in those contexts. ${ }^{153}$ Older patients (often

151. See, e.g., Alexander G. Fiks et al., Shared Decision-Making in Pediatrics: $A$ National Perspective, 126 PEDIATRICS 306 (2010) (providing a descriptive account of how often shared decision-making is used in pediatric contexts); Lainie Friedman Ross, Health Care Decisionmaking by Children-Is it in Their Best Interest?, 27 HasTINGS CTR. REP. 41 (1997) (cautioning against too much authority in patient (child) versus parent in pediatric setting); Monica E. Peek et al., Are There Racial Differences in Patients' Shared Decision-Making Preferences and Behaviors Among Patients with Diabetes?, 31 MED. DECISION MAKING 422 (2011) (examining racial differences in preferences and behaviors regarding shared decision-making); Lilisbeth Perestelo-Perez et al., Patient Involvement and Shared Decision-Making in Mental Health Care, 6 Current Clinical Pharmacology 83 (2011). A prominent U.S. mental health advocacy organization, Mental Health America, has even created a website specifically to promote shared decision-making. See You're on the Team: How Shared Decisionmaking Works, MENTAL HEALTH AM., http://www.nmha.org/go/youreontheteam/ howitworks (last visited Mar. 20, 2013).

152. See, e.g., Lisa J.M. Caldon et al., Clinicians' Concerns about Decision Support Interventions for Patients Facing Breast Cancer Surgery Options: Understanding the Challenge of Implementing Shared Decision-Making, 14 HEALTH EXPECTATIONS 133 (2010) (discussing shared decision-making in the context of breast cancer treatment decisions); Emmanuelle Bélanger et al., Shared Decision-Making in Palliative Care: A Systematic Mixed Studies Review Using Narrative Synthesis, 25 PAlliative MEd. 242 (2011) (providing a narrative synthesis of literature on shared decision-making in the palliative care context).

153. Atie van den Brink-Muinen et al., Preferences and Experiences of Chronically Ill and Disabled Patients Regarding Shared Decision-Making: Does the Type of Care to be Decided Upon Matter?, 84 Patient Educ. \& Counseling 111 (2011). 
thought to favor more paternalistic decision-making) found shared decision-making important and also were more likely to experience more involvement in decision-making in practice than were younger patients. ${ }^{154}$ Further, researchers reported that patients' preferences varied by context, with patients attaching greater importance to shared decisionmaking in occupational health-care contexts, less in medical care contexts, and the least in lifestyle choices. ${ }^{155}$ The authors suggested that

whether a patient wants to be involved in decision-making has been treated in most other research as some kind of trait characteristic of patients or at least determined by rather stable patient characteristics such as education, locus of control or self-efficacy. Few authors have suggested that patients' preferences and experiences may develop over time as people are more exposed or familiar with involvement in decision-making or vary from one situation or context to another for an individual patient. ${ }^{156}$

If a similar phenomenon occurs in supported decision-making modelswhich, given the parallels between shared and supported decisionmaking, seems plausible - preferences about supported decision-making processes may also vary by the sort of decision to be made. Alternatively, of course, the findings may simply reflect that the decisions involved are somewhat different: medical decisions such as treatment or medication choices, versus occupational health-care decisions such as when and whether to return to work. ${ }^{157}$ Such different decisions may be made with different supporters, and, thus, the relevant decision-making dynamics might be different.

Research on shared decision-making also suggests reason to question the extent to which individuals being supported actually want to be involved in decision-making. A systematic review of 69 "preferencematched" studies (i.e., studies that examined whether patient preferences matched what actually occurred) made two important findings as to shared decision-making. First, a "sizeable" minority of patients preferred a passive role (i.e., delegating decision-making to the physician) in decision-making, rather than a sharing or active role in decision-making. ${ }^{158}$ Indeed, in a number of the studies reviewed, a

154. Id. at 115. The former finding about importance placed on shared decisionmaking was consistent with previous shared decision-making research, but the latter finding was not. Id.

155. Id.

156. Id. at 116 (footnotes omitted).

157. Id. at 112 (Box 1).

158. Donald J. Kiesler \& Steven M. Auerbach, Optimal Matches of Patient Preferences for Information, Decision-Making and Interpersonal Behavior: Evidence, Models and Interventions, 61 PATIENT EDUC. \& COUNSELING 319, 330 (2006). 
majority of patients preferred a passive role. ${ }^{159}$ These findings highlight how critical it is to explore what proportion of those who participate in supported decision-making in fact want to be involved in the decisionmaking process (and to what extent). Second, although a number of studies in the review showed that matching preferences to actual experience led to positive outcomes (e.g., measured by patient satisfaction, adjustment, or symptom reduction), due to methodological limitations and "inconsistent" results, the authors were not comfortable concluding that this was so in all cases. ${ }^{160}$ A robust research program exploring the outcomes of successful preference-matching in the supported decision-making context will be of significant value.

A second key insight offered by the shared decision-making research is that training matters, but not just for those providing decisionmaking assistance. The literature emphasizes that effective shared decision-making may require education and training for both clinicians and patients. Clinicians might be taught, for instance, how to recognize when and how to use shared decision-making, how to collaborate effectively with patients, and how to discuss lifestyle or other "preference sensitive" decisions. ${ }^{161}$ Patients, too, might benefit from training, for instance in how to determine and communicate their preferences. ${ }^{162}$ As noted earlier, ${ }^{163}$ training and education of potential supporters is of paramount concern in the supported decision-making context, both to improve outcomes and to avoid manipulation or undue influence. The shared decision-making literature shows that education of the person being supported may be useful as well.

Finally, the shared decision-making literature suggests caution about claims that supported decision-making will lead to improved outcomes, whether psychological or otherwise. The literature has investigated whether engaging in shared decision-making in fact leads to better patient outcomes, such as increased satisfaction, treatment

159. See id. at 324 tbl.3.

160. See id. at 330 .

161. See, e.g., K.E. Hauer et al., Assessment of Medical Students' Shared DecisionMaking in Standardized Patient Encounters, 26 J. GEN. INTERNAL MED. 367 (2010) (calling for more education for clinicians regarding lifestyle discussions and collaboration with patients); van den Brink-Muinen et al., supra note 153, at 116 (arguing that, rather than searching for perfect "tool" for physicians to use to implement shared decisionmaking, greater physician awareness of its value is more critical).

162. See Angela Towle \& William Godolphin, Framework for Teaching and Learning Informed Decision Making, 319 BRITISH MED. J. 766 (1999); Kiesler \& Auerbach, supra note 158, at 335 (suggesting that focus on the patient would bear more fruit than seeking to alter clinician behaviors, and arguing for improving physician skills in tailoring shared decision-making approaches based on patient preferences).

163. See supra Part III.B.2.d. 
adherence, and actual health. Joosten et al.'s recent systematic review of the approach's effectiveness (vis-à-vis these outcomes) found some positive results where shared decision-making involved long-term decisions and/or chronic diseases in treatment programs involving more than one visit. ${ }^{164}$ Results, however, were mixed. Of eleven randomized control trials that fit the authors' inclusion criteria, nine focused on physical health and two focused on mental health conditions. Five of those eleven found no difference between the shared decision-making intervention and control group on outcome measures (all of which were in physical health and involved a single decision or one consultation); one of the eleven showed only long-term effects; and five of the eleven (including the two in mental health) showed improved outcomes. ${ }^{165}$ The most frequently studied outcome measure was patient satisfaction, yet only one study found improvement in patient satisfaction, and it involved shared decision-making in a mental health treatment program. ${ }^{166}$ Of the three studies that included an additional outcome of patient knowledge, two found an increase. ${ }^{167}$

Of course, as highlighted above, supported decision-making involves a broader range of decision-making contexts than mental health and medical decision-making, and this review found no benefits for physical health-care decisions. ${ }^{168}$ Moreover, one significant drawback of Joosten et al.'s review_-as with a number of the other overviews of the shared decision-making literature-is that the authors failed to include discussion of the strength of the effects they discussed. For instance, the review only reported that the studies reviewed "reported positive effects," or "found no difference between intervention and control" groups; nowhere did the review report or calculate effect sizes of those studies' data, as would be useful (if not essential) to evaluate the state of the literature in question. ${ }^{169}$ Furthermore, other reviews of shared decision-making are simply narrative, thus, again, missing the opportunity to meaningfully quantify the overall effect or usefulness of shared decision-making. ${ }^{170}$ Therefore, for shared decision-making literature reviews to be truly helpful for supported decision-making

164. E.A.G. Joosten et al., Systematic Review of the Effects of Shared DecisionMaking on Patient Satisfaction, Treatment Adherence and Health Status, 77 PSYCHOTHERAPY \& PSYCHOSOMATICS 219 (2008).

165. Id. at $222-23$.

166. Id. at 223 .

167. Id.

168. Id.

169. See generally Jeremy A. Blumenthal, Meta-Analysis: A Primer for Legal Scholars, 80 TEMP. L. REv. 201 (2007).

170. E.g., Bélanger et al., supra note 152. 
research (or, to be candid, for shared decision-making research itself), more detailed syntheses and meta-analyses, including summaries and comparisons of effect sizes, will need to be conducted. ${ }^{171}$

In sum, the shared decision-making literature provides some useful insights for supported decision-making researchers, although the analogy between the two approaches is a broad one. First, the literature reinforces the perspective that the context in which individuals face decisions is important to consider, not just personal characteristics of the person with a disability or of his or her supporters. Second, it is consistent with literature on supported decision-making that discusses the importance of educating the stakeholders involved about the most effective means of reaching a beneficial outcome (and, most likely, developing appropriate criteria for evaluating whether the outcome is beneficial at all), as well as a means of avoiding undue influence. Notably, the shared decision-making literature highlights that the principal stakeholder, the person with ID or other cognitive disability, might benefit from education and training as well, though the supported decision-making conversation has not reached that point. Yet the literature on shared decision-making also suggests that education alone may not be sufficient to guide supporter behavior; it may also be important to craft incentive structures that encourage particular behavior. ${ }^{172}$ Finally, this literature suggests types of research questions that we might wish to apply in the supported decision-making context. For instance, those seeking to understand supported decision-making should consider undertaking research similar to that which has been done in the shared decision-making context: among other things, (1) evaluating the preferences of persons with cognitive and intellectual disabilities in various contexts; (2) examining whether such preferences are matched in the real experience of supported decision-making; and (3)

171. An additional advantage of conducting such meta-analyses is that doing so addresses concerns such as the "heterogeneity of the samples, settings, and measurements [that] might affect the generalization of the results." Joosten et al., supra note 164, at 224. That is, Joosten and colleagues were concerned that differences among the studies being reviewed would vitiate the usefulness of a broad review. This is, however, precisely the purpose for which meta-analysis is useful, especially when moderator analyses are conducted-i.e., analyses that use differences across studies as evaluative criteria in and of themselves. See Blumenthal, supra note 169.

172. See Angela Coulter et al., Implementing Shared Decision Making in the UK, 105 Z. EVID. FORTBILD. QUAL. GESUNDHEITWESEN (ZEFQ) 300, 301 (2011) ("'TT]argets and centralised guidelines, supported by financial incentives and managerial imperatives, have had much greater impact on the way clinicians work than exhortations about patient-centred care.") Thus, for supported decision-making to be effective, it may require ensuring that decision-making supporters have not only the resources and skills they need to provide effective support but also the incentives to do so. 
assessing whether such a match has any effect on the process or substance outcomes of decision-making. ${ }^{173}$

\section{NEXT STEPS}

There is reason to be optimistic about the potential for supported decision-making processes to enhance the well-being of persons with cognitive and intellectual disabilities. Supported decision-making has the potential to provide individuals with cognitive and intellectual disabilities the help they may need to manage their affairs and make decisions about their own lives and, by so doing, to improve their wellbeing and promote their dignity.

Moreover, there are real problems with the current guardianship system, which making supported decision-making available might ameliorate. Most importantly, consistent with the notion that all people are entitled to live in the least restrictive manner practicable, guardianship should be imposed only when alternative mechanisms for meeting its objectives are not reasonably feasible. Thus, for example, guardianship should not be considered a routine part of permanency planning for persons with ID.

However, without viable alternative decision-making models such as supported decision-making, guardianship will likely continue to be treated as a routine response to the decision-making challenges facing persons with intellectual and cognitive disabilities instead of a true last resort. It is therefore important for policymakers to consider how supported decision-making systems might be institutionalized in the United States to better serve the needs of persons with cognitive and intellectual disabilities. ${ }^{174}$

Accordingly, policymakers should explore how supported decisionmaking could reduce the use of guardianship as well as how supported decision-making approaches could be integrated into guardianship systems. As explained earlier in this article, policymakers can promote supported decision-making either by creating opportunities and mechanisms for formally recognizing an individual's decision-making supporter or by creating opportunities and mechanisms for providing individuals with such supporters. ${ }^{175}$ Both approaches may be necessary

173. In another example of process versus substantive preferences, one study showed that simply engaging in shared decision-making leads to better outcomes on some measures than actually matching patient preference to experience. M. Gattellari et al., Sharing Decisions in Cancer Care, 52 Soc. SCI. \& MED. 1865 (2001).

174. Cf. KERZNER, supra note 33 , at 59 (noting that many of the supported decisionmaking processes available in Canada "are of no use to the many people who have no supports in their lives").

175. See supra Part II.B.1. 
in order for supported decision-making to benefit both those with and without pre-existing support networks.

Unfortunately, as this article has shown, the existing evidence base on supported decision-making is simply insufficient to know whether any given supported decision-making process can achieve its promise. To be sure, the goals of those promoting supported decision-making are generally laudable, and many of the problems that those seeking to move to a supported decision-making approach have identified are significant. However, little is known about how supported decision-making actually works in the jurisdictions where it is implemented. While there are some cursory data on demographics of individuals entering into supported decision-making agreements, it is clearly insufficient to understand to what extent the model will be considered attractive or workable across divergent populations. More importantly, there are virtually no data on how support is provided in supported decision-making relationships, including whether principals perceive it to in fact be "supportive" or are actually empowered by it. Nor are there data about the quality of the decisions reached under supported decision-making frameworks.

Given this dearth of information, it is simply too early to conclude that supported decision-making is an effective decision-making model, much less that supported decision-models should be institutionalized by state actors. It may well be that supported decision-making provides a meaningful, empowering alternative to more restrictive decision-making models such as guardianship. It may also be that supported decisionmaking is little more than a farce - a facade of support that, in fact, fails to provide it.

It is similarly too early to know whether certain forms of supported decision-making are more likely to achieve positive outcomes-either in terms of substance or in terms of process - than other forms. Thus, policymakers seeking to implement supported decision-making regimes have little guidance when choosing among different supported decisionmaking models.

Accordingly, significant research is needed to guide policy in this area if policymakers are to actually design and implement practices which effectively empower persons with intellectual and cognitive disabilities to engage to the fullest extent possible in decisions about their own lives. Our review of the existing literature on supported decision-making, combined with insight drawn from the related literatures on surrogate decision-making and shared decision-making, 
suggests five primary areas for future research on supported decisionmaking: ${ }^{176}$

1. How do persons with intellectual and cognitive disabilities and decision-making supporters interact with one another? What techniques do supporters use to attempt to support decisionmaking? How do persons with cognitive and intellectual disabilities react to these techniques? To what extent do techniques and reactions vary based on the form of supported decision-making, the context in which it takes place, or the age or disability of the principal?

2. Is supported decision-making coercive and, if so, under what circumstances? Specifically, to what extent do supporters engage in behaviors that are designed to be, or have the effect of being, controlling or otherwise coercive? To what extent do such behaviors depend on the form of the supported decisionmaking relationship or the personal or demographic characteristics of those involved in the relationship?

3. Do supported decision-making processes result in decisions that are substantively different than the decisions reached under surrogate decision-making models such as guardianship? If so, what are the differences, when do they occur, and why? To what extent do these differences advantage or disadvantage those involved in the supported decision-making relationship?

4. Do differences in supported decision-making techniques influence the decisions made and whether principals are satisfied or empowered by the process? If so, do such differences vary based on supporter and principal characteristics such as age or type of disability?

5. Can process or substantive outcomes of supported decisionmaking be improved by training to supporters, principals, or both? If so, what types of training are most effective and under what conditions?

176. See also Kohn \& Blumenthal, supra note 1 (providing a condensed overview of the state of the evidence on supported decision-making, and making parallel research recommendations). 
While investigating other questions would also be worthwhile, a focus on these five questions will help ensure that research findings are most useful in informing policy choices surrounding supported decisionmaking.

The answers to these questions would help indicate whether or not supported decision-making can achieve some or all of the goals its supporters envision, including whether it can ameliorate many of the problems associated with surrogate decision-making processes such as guardianship. Research into these questions could also indicate which forms of supported decision-making are most likely to achieve a particular goal or ameliorate a particular problem.

\section{CONCLUSION}

Supported decision-making holds promise as an alternative to surrogate decision-making. For example, it has the potential to be an empowering alternative to the much-maligned process of guardianship, as well as an empowering element of the guardian-ward relationship. The question, however, is whether supported decision-making can fulfill that promise. If it empowers persons with cognitive and intellectual disabilities to make decisions for themselves as its proponents claim, it would advance the interests and human rights of persons with disabilities. However, without more evidence as to how supported decision-making functions in practice, it is too early to rule out the possibility that it may frequently have the opposite effect. For example, there is reason to be concerned that supported decision-making may allow largely unaccountable third parties to improperly influence the decisions of persons with disabilities, thereby disempowering persons with disabilities and undermining their rights.

In light of the growing chorus of calls for expanding supported decision-making practices, including integration into the U.S. legal system, it is imperative that substantial further research be conducted to examine how supported decision-making actually operates. Specifically, research is needed to determine the extent to which supported decisionmaking approaches achieve their goals, and the conditions under which they are likely to do so. If supported decision-making policies are not guided and informed by such research, there is a risk that supported decision-making will not, in fact, be supportive of persons with cognitive and intellectual disabilities. 
